Research Article

\title{
Study on Crack Propagation of the Tunnel Model under Dynamic Loading
}

\author{
Chengxiao Li $\left(\mathbb{D},{ }^{1}\right.$ Yuantong Zhang, ${ }^{1}$ Peng $\mathrm{Xu}^{2}$ and Chen $\mathrm{An}^{1}$ \\ ${ }^{1}$ School of Mechanics and Civil Engineering, China University of Mining and Technology-Beijing, Beijing 100083, China \\ ${ }^{2}$ School of Mathematics and Physics, University of Science and Technology Beijing, Beijing 100083, China \\ Correspondence should be addressed to Chengxiao Li; licx93@163.com
}

Received 16 December 2020; Revised 6 April 2021; Accepted 15 April 2021; Published 26 April 2021

Academic Editor: Patrice Berthod

Copyright (C) 2021 Chengxiao Li et al. This is an open access article distributed under the Creative Commons Attribution License, which permits unrestricted use, distribution, and reproduction in any medium, provided the original work is properly cited.

Crack defects make it difficult to predict the dynamic fracture of tunnel specimens under an impact load. To study the impact of the velocity and crack location on a roadway under dynamic load, specimens with tunnel-type voids were made using polymethyl methacrylate. The split-Hopkinson bar was used as the loading method, and a digital laser dynamic caustics system was used to observe the fracture process of the specimens. The dynamic fracture process was evaluated by the crack propagation velocity, displacement, and dynamic stress intensity factor. To predict and verify the test results, ABAQUS was used to simulate the test process. It was found that the results of the simulated combinations of the crack propagation path and initial fracture toughness change law are consistent with the test results. The initial fracture toughness and the peak value of the crack propagation velocity increased with the increase of the impact velocity. The crack propagation law and trajectory were affected by the location of the prefabricated cracks.

\section{Introduction}

Rapid industrial and economic development has increased the demand for mineral resources, which is gradually decreasing or depleting the reserves of surface mineral resources. In response, resource exploration has turned to deep underground areas. The roadway is the most basic link to underground operations. However, in the process of excavation or maintenance, roadways may be affected by various impact loads, such as the impact of rocks falling from different heights or the impact of shock waves caused by explosions. Moreover, if there are cracks in the rocks surrounding the roadway, the impact will cause these cracks to expand, thus reducing the stability of the roadway structure. Cracks in the rocks surrounding the roadway also affect the direction, speed, and dynamic fracture toughness of crack propagation in varying degrees. Owing to the difficulty of directly observing the fracture process of rock materials, the effects of the impact velocity and crack location on a roadway are studied using polymer materials with high light-transmission and optical systems.
The impact of dynamic loads on roadways has long been a hot topic of research. Researchers have made significant progress through experiments or numerical simulations [1-5]. Explosives or mechanical crushing are frequently used in roadway excavation and mining to conserve human resources and increase work efficiency. In the process of using these technologies, a large number of cracks are produced at different locations on the roadway, which reduce its stability. Many researchers have studied the effect of dynamic loads on crack growth. For example, Guo studied the effect of explosions on cracks in adjacent roadways and found that stress concentration at the cracks was caused by explosioninduced stress waves $[6,7]$. Zhou studied the crack propagation behavior of a rock roadway model under the impact of a large-scale drop hammer by numerical simulations [8-12]. Fan studied the stress intensity factor at the crack tip and determined the stress function of a roadway with radial cracks under compression [13]. Huang studied the influence of a weak interlayer on the failure of surrounding rocks under dynamic load by a model test [14]. Feng used dynamic crack propagation to study the macro instability mechanism of roadway rockburst [15]. 
Owing to the influence of the split-Hopkinson bar (SHPB) air pressure system, roadway model materials, friction, and other external factors, various accidents may occur during the crack propagation process and along the crack trajectory after the roadway is impacted. Thus, there may be errors in the results of pure experiments. To obtain a universal law, numerical simulations should be conducted to reinterpret the test process. If the simulation results are similar to the test results, then the accuracy of the test can be verified, and relevant conclusions can be drawn. ABAQUS is a commercial finite element software for numerical simulations that is widely used in fracture process research. It includes the extended finite element method (XFEM), which has been successfully applied in the field of crack propagation research [16-19].

In this study, the SHPB technique is used as the impact load to build a digital laser caustic platform to observe the crack growth process of a polymethyl methacrylate (PMMA) tunnel specimen under impact. The caustic method is used to study the changes in the velocity, dynamic stress intensity factor (DSIF), and initial dynamic fracture toughness in crack propagation processes for a roadway with different impact velocities and crack positions. ABAQUS was also used to simulate the test process to verify the crack propagation trajectory and initial fracture toughness.

\section{Testing System}

2.1. Theoretical Analysis of the Caustic Curve. In the process of solid material fracture research, the stress parameters corresponding to specific points are controlled by singularities. The high-strain area formed near the singular point is small. Although the ordinary strain gauge method can measure the strain state at a certain point; when the size of the strain gauge exceeds the strain area near the singular point, the strain value obtained will be inaccurate. This is a difficult problem in fracture mechanics, i.e., the accurate measurement of stress parameters in the high-strain zone near the singular point. In 1964, Manogg proposed a caustic method to solve the singularity problem. A method was also proposed to determine the stress intensity factor based on the characteristic size of the caustic spots at the crack tip [20]. Theocaris derived the reflection from the caustic method and studied the strain field at the crack tip of metal materials under the condition of caustic reflection [21, 22]. Yang and Yang established a new type of digital laser dynamic caustics experimental system consisting of a digital laser system and a high-speed camera system [23]. On this basis, the caustic method is widely used to study the dynamic fracture process of materials [24-26].

The thickness of a transparent solid model plane is uniform under ideal conditions and changes under the action of an external load. Hence, the thickness of the area near the singular point is no longer uniform. The deformation of the model changes its thickness and refractive index. When parallel rays are incidentally perpendicular to the model's plane, the reflected and refracted lights emitted from the front and back surfaces of the model are no longer parallel rays. When the deformation of the model reaches a certain level, the light passing through the model will be projected onto a caustic surface in three-dimensional space. If a reference plane parallel to the model plane is placed at a distance of $Z_{0}$ from the model, then the cross section of the caustic surface can be observed on this reference plane (Figure 1). The cross section is surrounded by the bright curve of the outer circle with the inner black area, and this black area is the caustic spot. Figures 2(a) and 2(b) show the cross-sectional views of the caustic surface type I and mixed type I-II cracks obtained by the digital laser dynamic caustics (DLDC) system, respectively.

If a point $K(x, y)$ exists on the specimen, there will be a corresponding point $K^{\prime}\left(x^{\prime}, y^{\prime}\right)$ on the reference surface. This relationship can be expressed as follows [27]:

$$
\vec{X}=\vec{x}+\vec{w}
$$

where $\vec{w}$ is the vector of the specimen deflected toward the reference plane by the distance $Z_{0}$, which can be expressed as

$$
\vec{w}=-Z_{0} \operatorname{grad} \Delta s_{r, t}(x, y)
$$

Here, $\Delta s_{r, t}$ is the variation of light passing through the specimen, which can be expressed as

$$
\Delta s_{r, t}=\varepsilon d c_{r, t}\left[\left(\sigma_{1}+\sigma_{2}\right) \pm \xi_{r, t}\left(\sigma_{1}-\sigma_{2}\right)\right]
$$

where $\varepsilon$ is a constant and usually takes 1 or $2, d$ is the thickness of the specimen, $\xi_{r, t}$ is the light anisotropy coefficient of the material, and $c_{r, t}$ is the stress-optic constant.

If the growth of the crack length after time $\Delta t$ is set as $\Delta z$, $\Delta t$ at any time $t_{\mathrm{i}}$ can be expressed as

$$
\Delta z\left(t_{i}\right)=\sqrt{\Delta x^{2}\left(t_{i}\right)+\Delta y^{2}\left(t_{i}\right)},
$$

where $\Delta x\left(t_{i}\right)$ and $\Delta y\left(t_{i}\right)$ are the displacements along the $x$ axis direction and $y$-axis direction at time $t_{\mathrm{i}}$ during the crack propagation process. The crack growth rate $v$ is obtained by the differential of the crack length and time intervals.

According to the caustic theory, the caustic curve equation of the specimen in the reference plane can be expressed as

$$
\begin{gathered}
x I=r_{0}\left\{\cos \left(\theta+2 \arctan \frac{K_{\mathrm{II}}}{K_{\mathrm{I}}}\right)+\frac{2}{3} \cos \left[\frac{3}{2}\left(\theta+2 \operatorname{acrtan} \frac{K_{\mathrm{II}}}{K_{\mathrm{I}}}\right)\right]\right\} \lambda_{m}, \\
y^{\prime}=r_{0}\left\{\sin \left(\theta+2 \operatorname{acrtan} \frac{K_{\mathrm{II}}}{K_{\mathrm{I}}}\right)\right. \\
\left.+\frac{2}{3} \sin \left[\frac{3}{2}\left(\theta+2 \operatorname{acrtan} \frac{K_{\mathrm{II}}}{K_{\mathrm{I}}}\right)\right]\right\} \lambda_{m}
\end{gathered}
$$

where $\lambda_{m}$ is the magnification of light and $r_{0}$ is the radius of the initial curve and can be expressed as

$$
r_{0}=\left(\frac{3 \varepsilon Z_{0} d c_{r, t}}{2 \lambda_{m} \sqrt{2 \pi}}\right)^{2 / 5}\left(K_{I}^{2}+K_{I I}^{2}\right)^{1 / 5} .
$$

The mode I and II dynamic crack stress intensity factors, $K_{\mathrm{I}}^{d}$ and $K_{\mathrm{II}}^{d}$, can be expressed as 


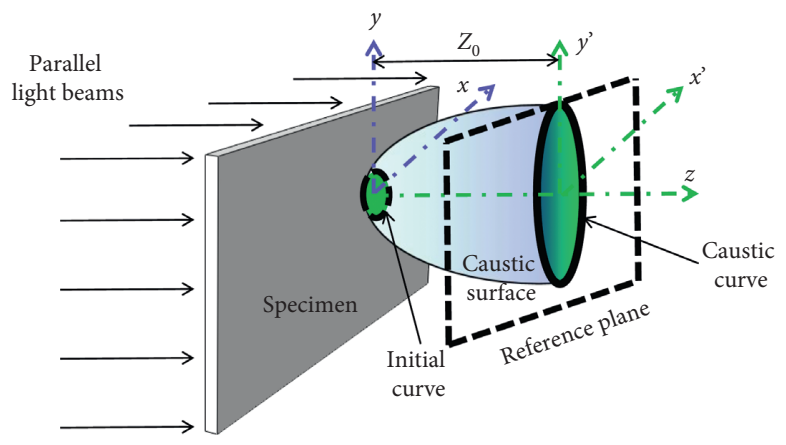

Figure 1: Caustic principle.

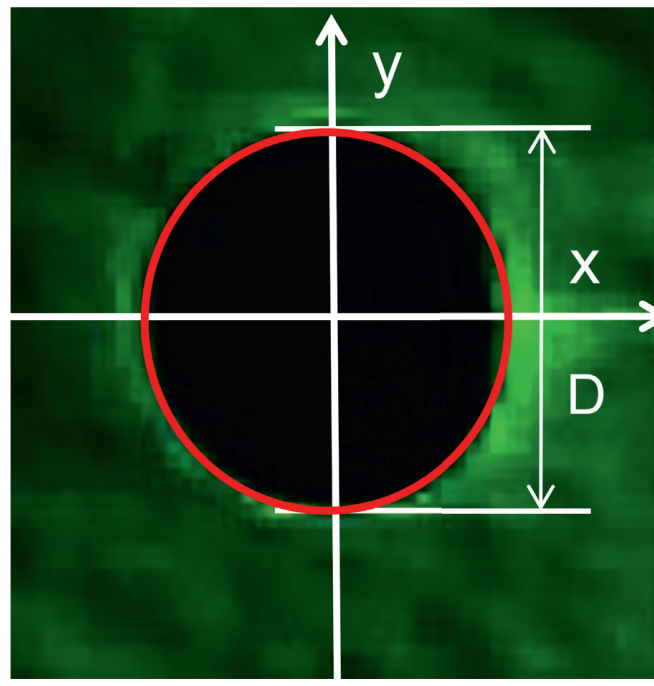

(a)

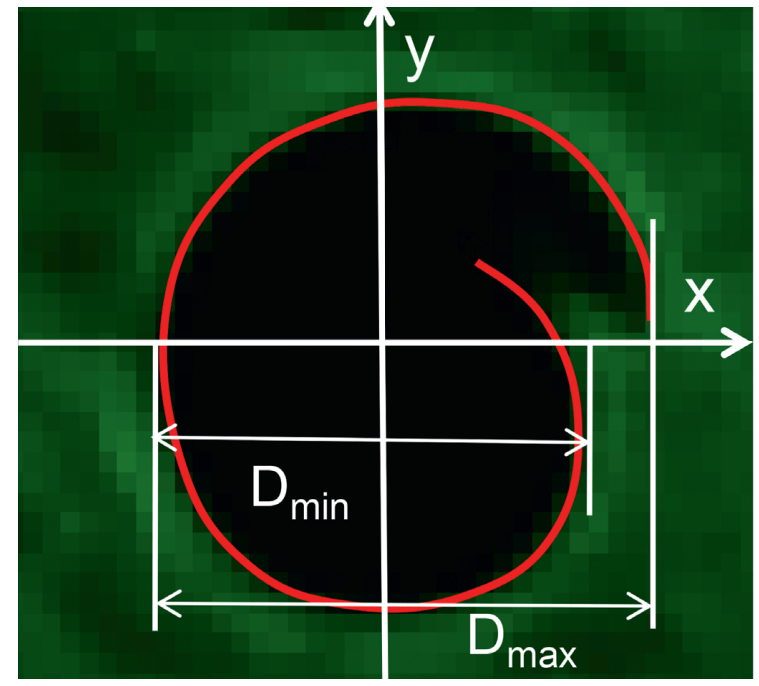

(b)

FIgUre 2: Two types of caustic images. (a) Mode I caustic spot. (b) Mixed mode I-II caustic spot.

$$
\begin{aligned}
K_{I}^{d} & =\frac{2 \sqrt{2 \pi} F(v)}{3 g^{5 / 2} z_{0} c d} D_{\max }^{5 / 2}, \\
K_{I I}^{d} & =\mu K_{I}^{d},
\end{aligned}
$$

where $g$ is the stress intensity factor coefficient and is equal to $3.17, D_{\max }$ is the maximum diameter of the caustic spot, and $\mu$ is the scale factor. $F(\nu)$ is the speed adjustment factor, which can be expressed as

$$
F(\nu)=\frac{4 \beta_{1} \beta_{2}-\left(1+\beta_{2}^{2}\right)^{2}}{\left(1+\beta_{2}^{2}\right)\left(\beta_{1}^{2}-\beta_{2}^{2}\right)},
$$

where $\beta_{i}^{2}=1-\left(\nu / c_{i}\right)^{2}, i=1$ and 2 , and $c_{1}$ and $c_{2}$ are the compressive and shear wave velocities, respectively.

2.2. Principles of the SHPB Test. The advantage of the SHPB is that it can avoid the direct measurement of the state of the specimen under a high-strain rate. When the projectile hits the incident rod, a compression wave propagates toward the specimen. Because the wave impedances of the incident bar and the specimen are inconsistent, the reflected wave is generated at the end-face of the incident bar, while the transmission wave is generated at the end-face of the transmission bar. When performing an impact test on the specimen, the strain gauges attached to the incident bar and transmission bar can be used to measure the stress and strain signals (Figure 3 ). The measurement results are stored in the super dynamic strain gauges as electrical signals. To reduce the wave dispersion effect, a rubber sheet is placed on the contact surface of the bullet and incident bar as a wave shape. According to the one-dimensional stress wave theory, the forces on the incident bar and transmission bar can be calculated according to the signal measured by the strain gauge. The formulas are given as follows:

$$
\begin{aligned}
& \sigma_{1}=\frac{S E_{b}}{S_{0}}\left(\varepsilon_{i}+\varepsilon_{r}\right), \\
& \sigma_{2}=\frac{S E_{b}}{S_{0}} \varepsilon_{t},
\end{aligned}
$$

where $\varepsilon_{i}$ is the incident wave, $\varepsilon_{r}$ is the reflected wave, $\varepsilon_{t}$ is the transmitted wave, $S$ is the cross-sectional area of the bar, $E_{b}$ is the elastic modulus of the bar, and $S_{0}$ is the cross-sectional area of the specimen. 


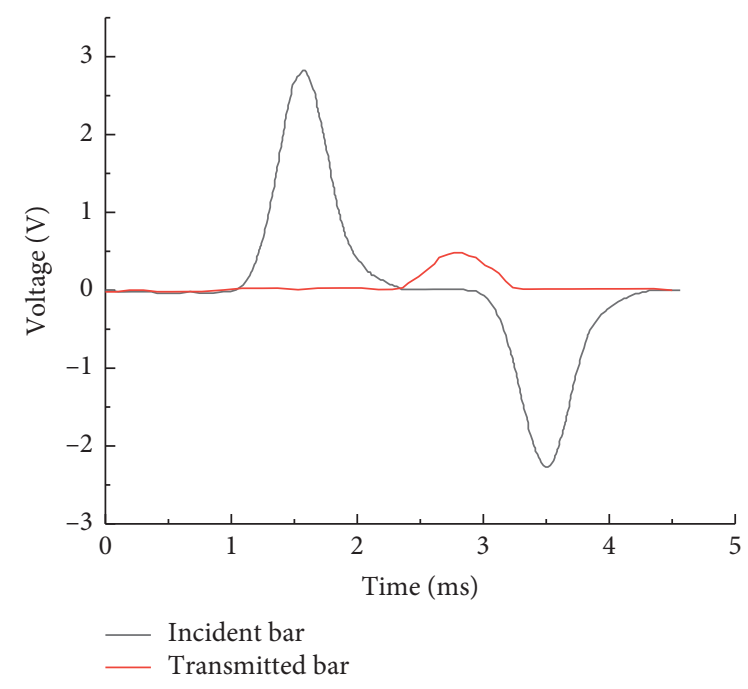

FIgURE 3: Typical voltage data of the gauges on the incident and transmitted bars.

The stress curve is obtained by superposition of the incident wave and reflected wave (Figure 4). Here, the slope corresponding to the rising part of the dynamic load curve is defined as the dynamic loading rate, which can be obtained by derivation using Origin software [28, 29].

2.3. Introduction of the Testing System. The test used an SHPB as the loading method to control the impact load. At the same time, a new DLDC system was used to observe the fracture process. The system diagram is shown in Figure 5. The DLDC system consists of a high-speed camera (FastcanSA5(16G): Photron Company, Japan), field lenses (1500 mm focal length and $300 \mathrm{~mm}$ diameter), beam expander (LCht$3 \mathrm{X}-532 \mathrm{~nm}$ : Edmund Optics Company, USA), and green laser (LWGL300-1500 mW: $50 \mathrm{~mW}$ ). In the experiment, the laser beam emitted by the laser beam expander diverged. Then, through the field lenses 1, PMMA specimen, and field lenses 2 , the final image was captured by the high-speed camera.

The SHPB system has three main parts: SHPB bars, an air pressure control system, and a strain acquisition system. The SHPB bars consist of a bullet, incident bar, and transmission bar with lengths of $400 \mathrm{~mm}, 2000 \mathrm{~mm}$, and $1800 \mathrm{~mm}$, respectively. The material is a cylindrical steel rod. The elastic modulus of the rod, $E_{b}$, is $206 \mathrm{GPa}$, and the longitudinal wave velocity is $5123 \mathrm{~m} / \mathrm{s}$. The strain acquisition system consists of a normal strain gauge and a super dynamic strain gauge (DC-97A), which were attached to the middle of the incident bar and transmission bar, respectively.

\section{Experimental Setup}

3.1. Specimen Design. Figure 6 shows the geometric dimensions of the tunnel-type specimen model. According to the actual engineering background, it was assumed that the width and height of the roadway were $8 \mathrm{~m}$ and $10 \mathrm{~m}$, respectively, while the radius of the semicircular arch was $4 \mathrm{~m}$. In the test, the roadway size was reduced according to the

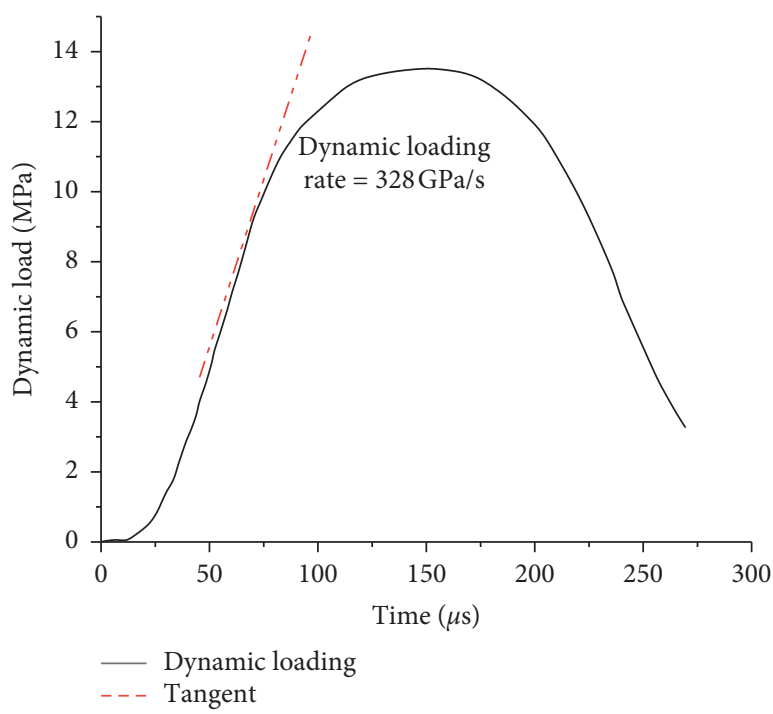

FIgURE 4: Dynamic load versus time curves.

similarity ratio of $400: 1$. The width and height of the roadway model were $20 \mathrm{~mm}$ and $25 \mathrm{~mm}$, and the radius of the semicircular arch was $10 \mathrm{~mm}$. The outer area of the roadway is a rectangular plate with a length of $140 \mathrm{~mm}$, a width of $70 \mathrm{~mm}$, and a thickness of $10 \mathrm{~mm}$. Prefabricated cracks with a length of $15 \mathrm{~mm}$ were set at different positions on top of the semicircular arch. The distance between the prefabricated crack and the central axis of the specimen is $a$. The crack positions in the test were set at $a=0 \mathrm{~mm}, 5 \mathrm{~mm}$, and $10 \mathrm{~mm}$. The width of the prefabricated crack was $0.5 \mathrm{~mm}$. PMMA, which has excellent mechanical and optical properties, is a typical brittle material often used in combination with optical systems to study crack propagation [30, 31]. Therefore, PMMA was selected as the material of the roadway model. The relevant parameters are listed in Table 1[32].

Owing to the size restrictions of the SHPB in the actual test process, the size of the rectangular plate outside the roadway cannot reach infinity. At the same time, it is necessary to ensure that the semicircular arch tunnel in the middle of the specimen has a certain size. To reduce the influence of the specimen boundary on crack propagation, the width of the specimen is slightly larger than the diameter of the SHPB $(50 \mathrm{~mm})$ when designing the specimen size. This ensures that when the SHPB impacts the specimen, the stress wave will affect the crack within the purple dotted line shown in Figure 7 to reduce the interference of the upper and lower boundaries on the crack propagation. The principle of specimen length selection is as long as possible. However, it is affected by the elastic modulus, shear modulus, and thickness of the specimen itself. To prevent the test piece from longitudinally breaking from the middle part during the impact, the improved length obtained by the repeated experiments is $140 \mathrm{~mm}$. In many sets of tests, crack propagation often occurs in the purple area, and very few tests have shown crack propagation in the red area. When the crack propagates in the red area, it is affected by the left boundary and suddenly deflects. Therefore, the effective 


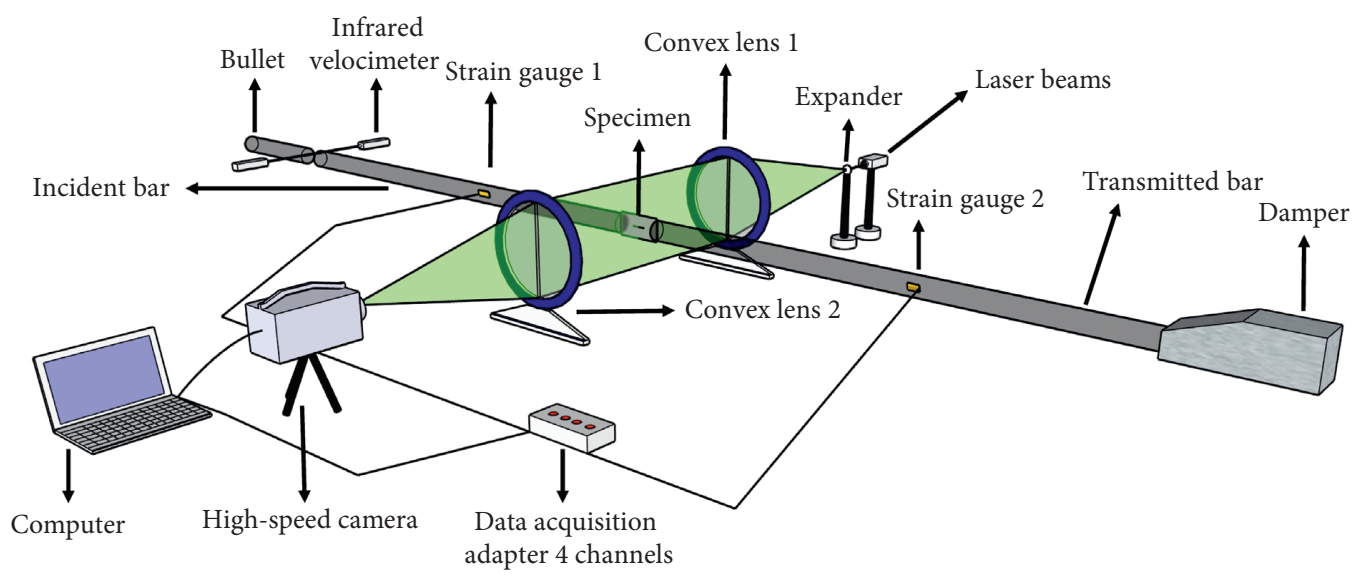

Figure 5: Test system.

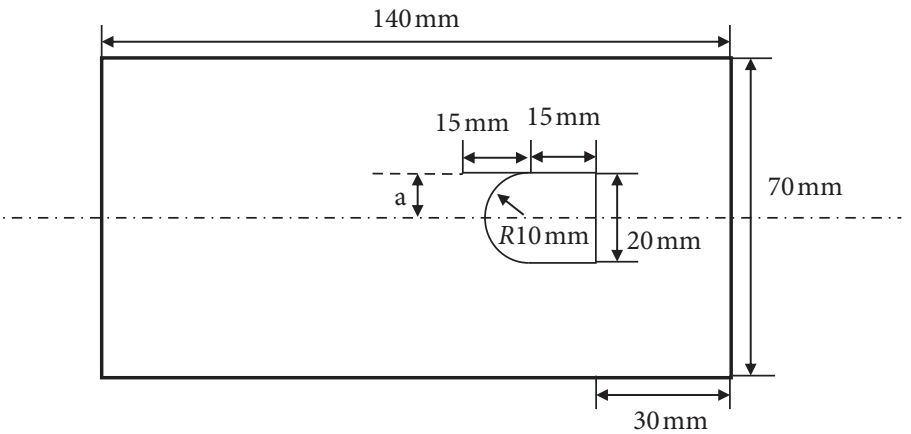

(a)

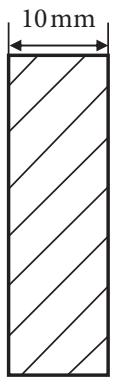

(b)

Figure 6: Specimen geometry.

TABLE 1: Mechanical properties of the PMMA.

\begin{tabular}{lccc}
\hline Mechanical properties & Symbols & Units & PMMA \\
\hline Density & $\rho$ & $\mathrm{kg} / \mathrm{m}^{3}$ & 1180 \\
Dynamic Young's modulus & $E_{d}$ & $\mathrm{GPa}$ & 6.1 \\
Poisson's ratio & $V_{d}$ & - & 0.31 \\
Velocity of compressive waves & $C_{p}$ & $\mathrm{~m} / \mathrm{s}$ & 2320 \\
Velocity of shear waves & $C_{s}$ & $\mathrm{~m} / \mathrm{s}$ & 1260 \\
Stress optical constant & $C$ & $\mathrm{~m}^{2} / \mathrm{N}$ & $0.88 \times 10^{-10}$ \\
Shear modulus & $G$ & $\mathrm{GPa}$ & 1.28 \\
\hline
\end{tabular}

range of the crack propagation in this study is within the purple dashed box.

3.2. Test Operation. To build a DLDC system, all the equipment must be placed in a suitable horizontal position to ensure that the laser can enter the surface of the specimen vertically. The resolution of the high-speed camera was $65100 \mathrm{fps}$, with $448 \times 224$ pixels. Experimenter A was responsible for adjusting the air pressure of the projectile. Because of the movement difference between the contact surface of the compression bar and the specimen in the transverse direction, there was a friction force in the test process. This prevented the transverse deformation of the contact surface between the specimen and the bar, which destroyed the one-dimensional stress state of the specimen, and caused its abnormal fracture. Therefore, during the SHPB experiment, the bar in contact with both ends of the specimen should be lubricated, such as the application of Vaseline. After the above procedures, when Experimenter B heard the sound of the impact, he immediately pressed the video button. In this experiment, the high-speed camera went into the posttrigger mode to record the picture within $2 \mathrm{~s}$ before the button was pressed to ensure that the test process could be fully recorded.

\section{Experimental Results}

4.1. Effect of the Impact Speed. Figure 8 shows the dynamic caustics diagram of the fracture process of the roadway model specimens under different impact speeds when $a=0 \mathrm{~mm}$. It can be seen from Figure 8 that when the prefabricated crack is on the central axis of the roadway, the final distance of the crack propagation is dependent on the impact velocity. At the low impact velocity $(V=3.32 \mathrm{~m} / \mathrm{s})$, the final crack propagation distance is very short. As the impact velocity increased, the crack propagation distance gradually increased. Moreover, it can be observed that the shape of the caustic spot is consistent with the type I focal speckle in Figure 2(a) from the point where the specimen was impacted and the tip of the prefabricated crack produced a focal speckle, until the crack stopped growing. It can 


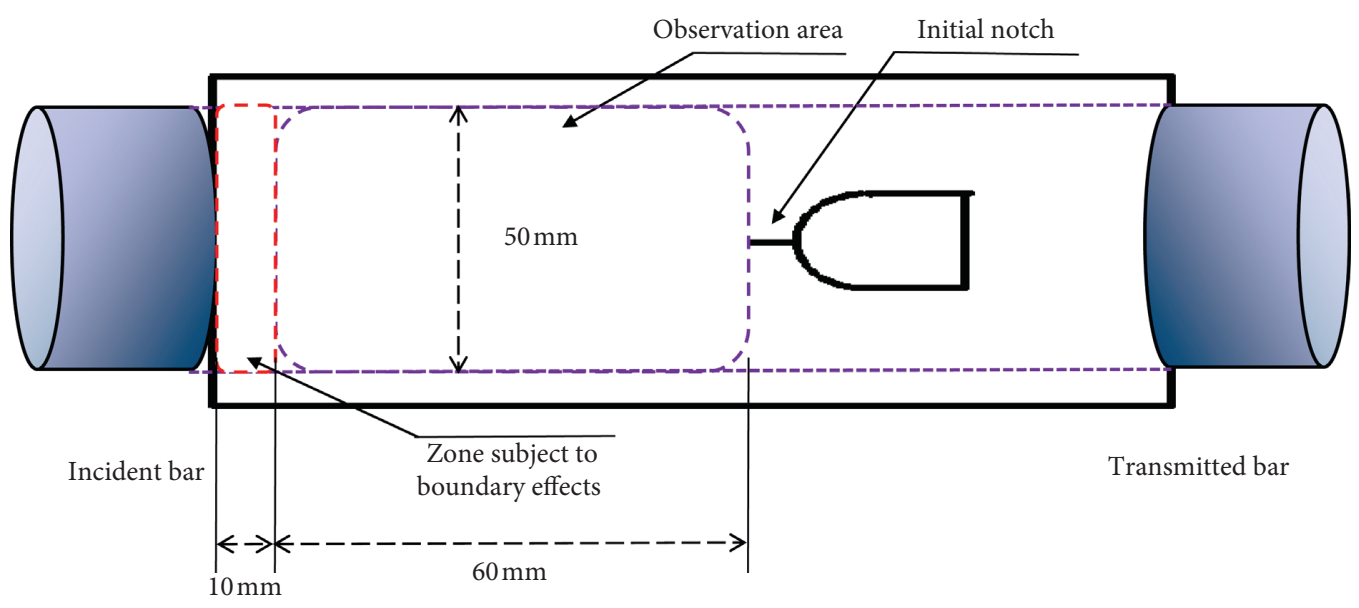

Figure 7: Schematic diagram of the specimen.

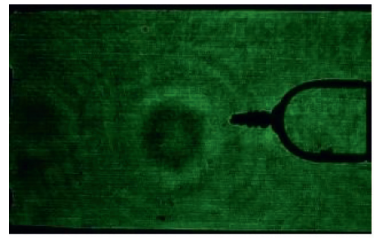

$0 \mu \mathrm{s}$

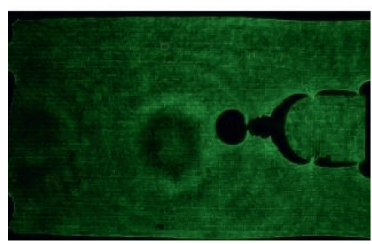

$800 \mu \mathrm{s}$

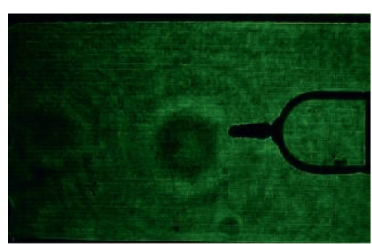

$0 \mu \mathrm{s}$

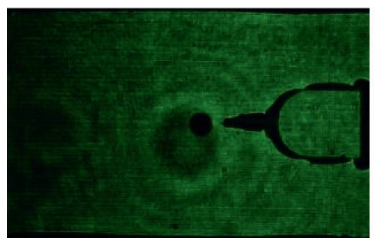

$866.66 \mu \mathrm{s}$

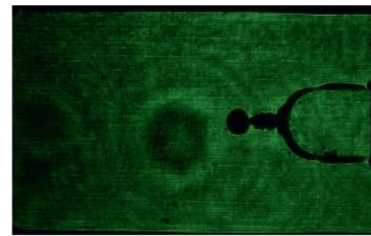

$66.66 \mu \mathrm{s}$

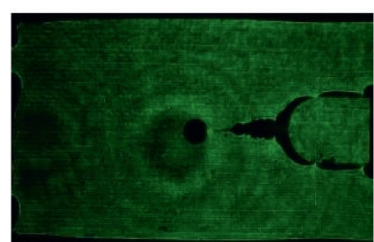

$1000 \mu \mathrm{s}$

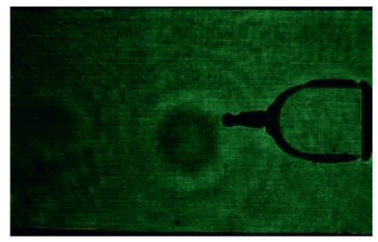

$53.33 \mu \mathrm{s}$

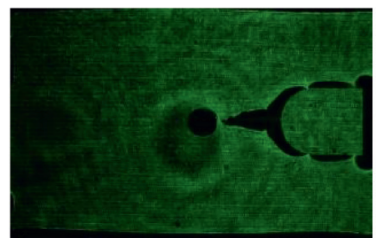

$1426.66 \mu \mathrm{s}$

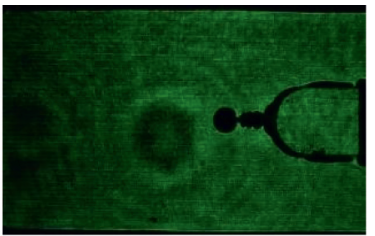

$133.33 \mu \mathrm{s}$

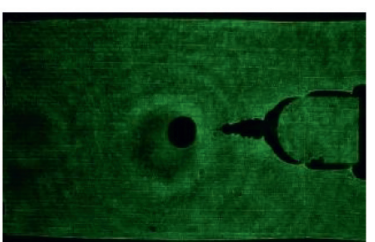

$1133.33 \mu \mathrm{s}$

(a)

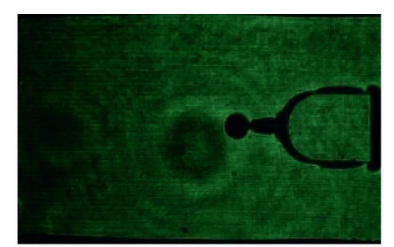

$173.33 \mu \mathrm{s}$

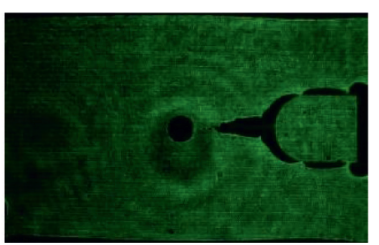

$1586.66 \mu \mathrm{s}$

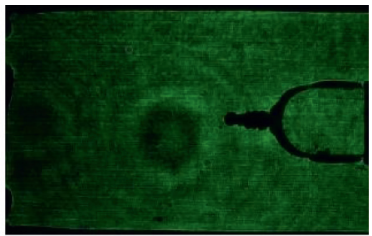

$560 \mu \mathrm{s}$

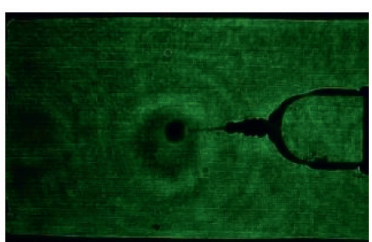

$1133.33 \mu \mathrm{s}$

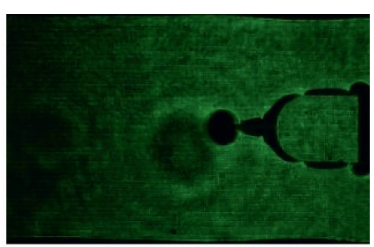

$679.99 \mu \mathrm{s}$

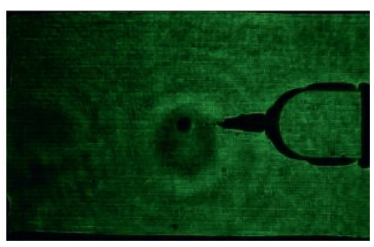

$1866.66 \mu \mathrm{s}$

(b)

Figure 8: Continued. 


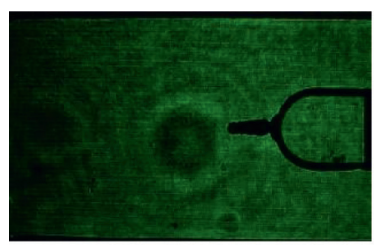

$0 \mu \mathrm{s}$

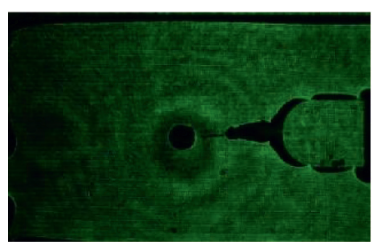

$706.66 \mu \mathrm{s}$

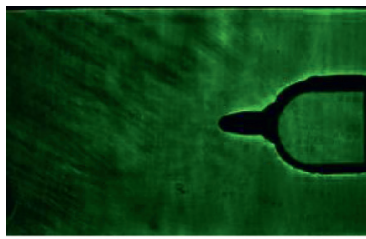

$0 \mu \mathrm{s}$

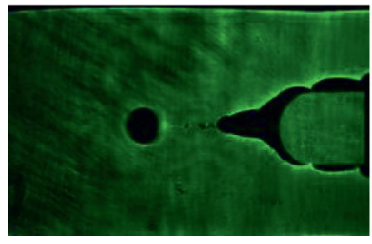

$1213.51 \mu \mathrm{s}$

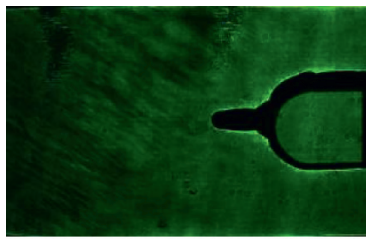

$0 \mu \mathrm{s}$

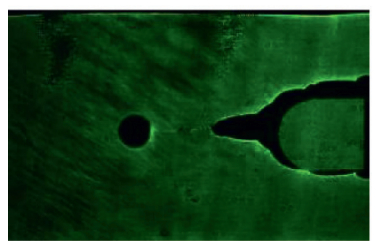

$660.52 \mu \mathrm{s}$

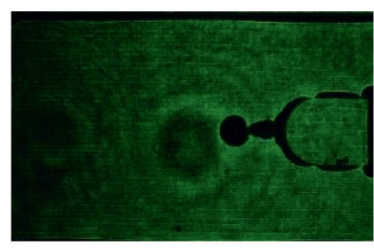

$120 \mu \mathrm{s}$

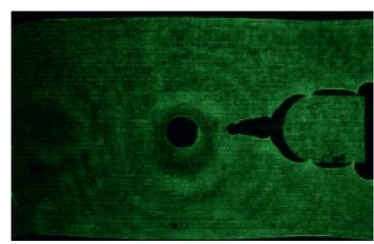

$840 \mu \mathrm{s}$

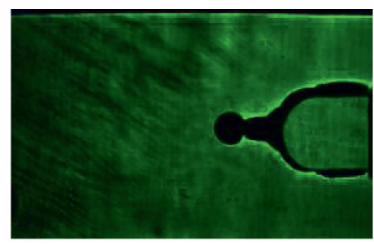

$61.44 \mu \mathrm{s}$

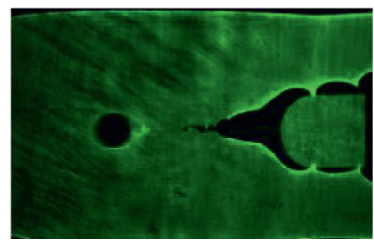

$1658.98 \mu \mathrm{s}$

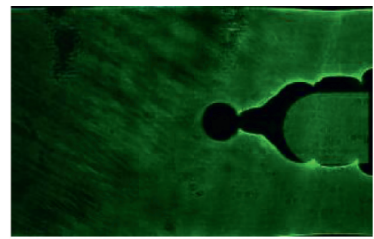

$122.88 \mu \mathrm{s}$

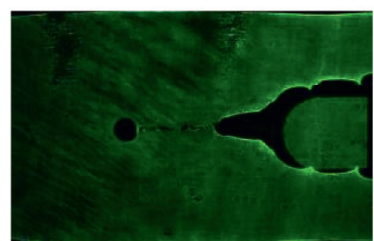

$986.66 \mu \mathrm{s}$

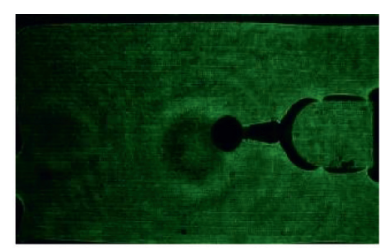

$466.66 \mu \mathrm{s}$

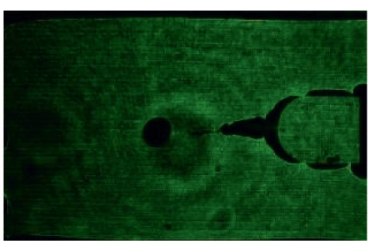

$1013.33 \mu \mathrm{s}$

(c)

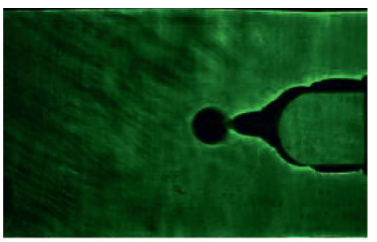

$291.85 \mu \mathrm{s}$

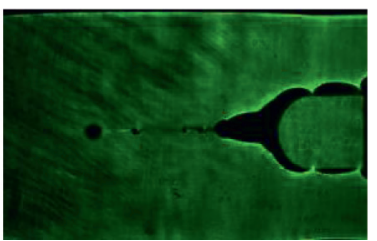

$1781.87 \mu \mathrm{s}$

(d)

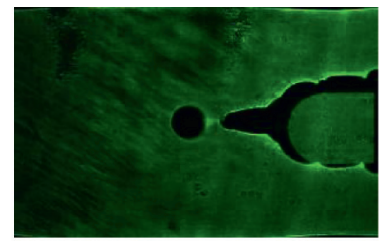

$322.58 \mu \mathrm{s}$

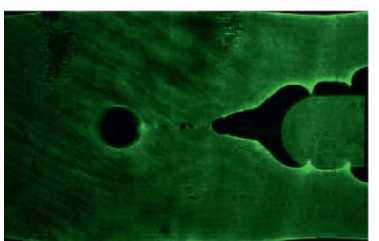

$1453.33 \mu \mathrm{s}$

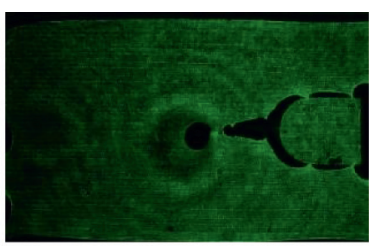

$533.33 \mu \mathrm{s}$

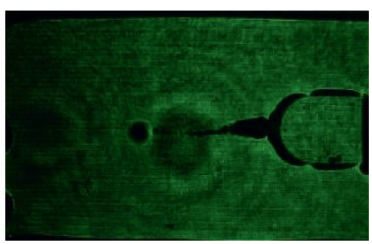

$1383.66 \mu \mathrm{s}$

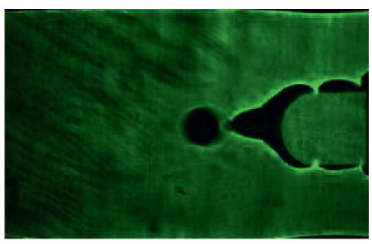

$860.21 \mu \mathrm{s}$

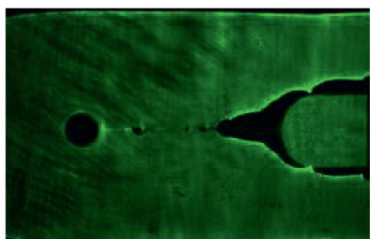

$2457.75 \mu \mathrm{s}$

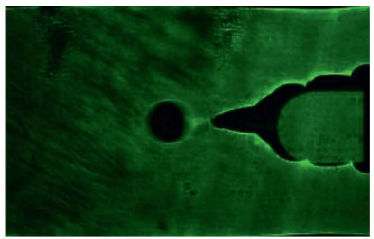

$460.82 \mu \mathrm{s}$

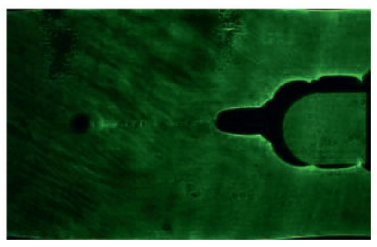

$1766.51 \mu \mathrm{s}$

(e)

FIgURE 8: Continued. 


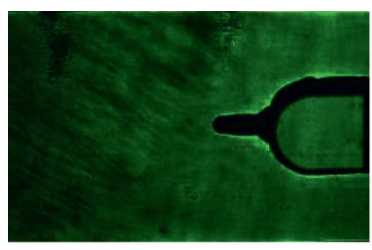

$0 \mu \mathrm{s}$

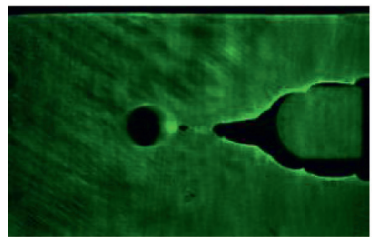

$1520.73 \mu \mathrm{s}$

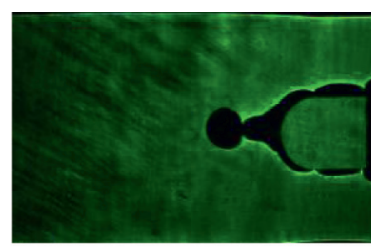

$261.13 \mu \mathrm{s}$

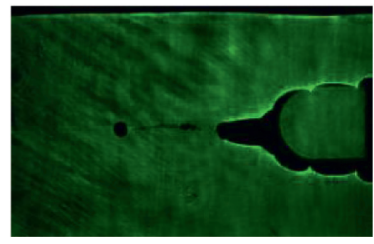

$2457.75 \mu \mathrm{s}$

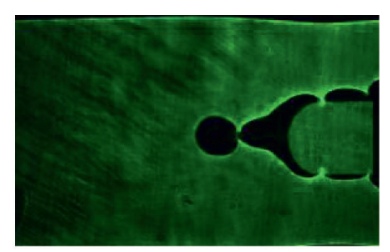

$829.49 \mu \mathrm{s}$

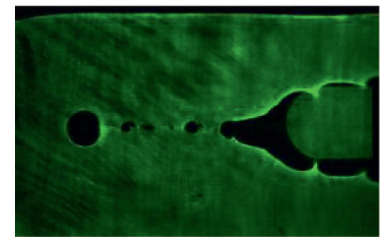

$2749.61 \mu \mathrm{s}$

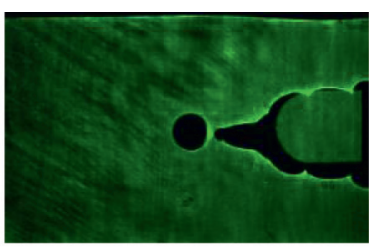

$1182.79 \mu \mathrm{s}$

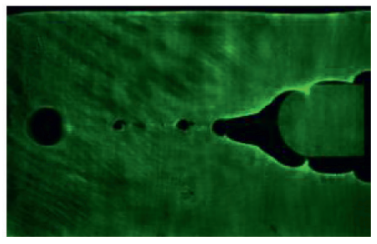

$2903.22 \mu \mathrm{s}$

(f)

Figure 8: Dynamic caustic image patterns on the tunnel model specimen under different impact speed conditions. (a) $V=3.32 \mathrm{~m} / \mathrm{s}$. (b) $V=3.78 \mathrm{~m} / \mathrm{s}$. (c) $V=4.28 \mathrm{~m} / \mathrm{s}$. (d) $V=4.53 \mathrm{~m} / \mathrm{s}$. (e) $V=4.79 \mathrm{~m} / \mathrm{s}$. (f) $V=5.16 \mathrm{~m} / \mathrm{s}$.

also be observed from the dynamic caustics diagram that the crack propagation trajectory at the six sets of speeds is almost along the central axis, and the resulting crack path is approximately a straight line. This indicates that when the prefabricated crack is at the central axis of the roadway, the crack propagates according to the type I crack after being subjected to an impact load, and the crack propagation type will not be affected by the change in the impact speed.

Owing to the limited exposure time of the high-speed camera, the outer edge of the image captured as the focal speckle moves will be blurry. This ambiguity is the main reason for the errors in the test results. The defocusing and binarization techniques in MATLAB were used to process the contour of the caustics. It can be seen from equations (8) and (9) that the values of $K_{\mathrm{I}}^{d}$ and $K_{\mathrm{II}}^{d}$ are linearly related to the two-fifths power of the caustics diameter. If the focus speckle contour processing is not sufficiently accurate, then the error of the calculated DSIF value will be magnified several times. Therefore, after the accurate processing of the contour of the caustics, an image analysis software was used to obtain the accurate radius of the caustics.

Figure 9 shows the variations in the DSIF of the mode I crack over time at different impact velocities, calculated by the caustics method when $a=0 \mathrm{~mm}$. The initial energy accumulation stage (IEAS) is the period between the changes in the caustics at the crack tip and the first movement of the crack. It can be observed that the duration of the IEAS of each group is affected by the impact velocity. At a low speed, e.g., $V=3.32 \mathrm{~m} / \mathrm{s}$, the duration of the IEAS is $t=800 \mu \mathrm{s}$. As the impact speed increased, the duration of the IEAS for each test specimen became $679.99 \mu \mathrm{s}, 466.66 \mu \mathrm{s}, 240 \mu \mathrm{s}, 122.88 \mu \mathrm{s}$, and $261.13 \mu \mathrm{s}$. This shows that as the impact speed increased, the duration of the IEAS gradually decreased. However, when the impact speed increased to a certain value, it is less likely that this trend would rebound. This is consistent with the prevailing knowledge that under the action of a high impact velocity or stress wave, the dynamic load will be applied to the specimen at a faster rate. Hence, the duration of the IEAS of the specimen is reduced.
When the crack completes the IEAS, the crack starts to expand, and the corresponding value of $K_{\mathrm{I}}^{d}$ is the initial fracture toughness $K_{I C}$ of the specimen. It can be observed that as the impact velocity increased, the initial fracture toughness of the material also increased (Figure 9). The reason for this phenomenon is that when the impact velocity increased, the stress wave transmitted from the incident bar more quickly acted on the crack tip. The stress concentration at the crack tip rapidly increased, and the crack started to grow. When the impact velocity is low, the stress concentration at the crack tip cannot quickly reach a large value. Hence, the specimen cannot fracture, and the DSIF at the crack tip will decrease. As the stress wave is reflected and acts on the crack tip, the DSIF at the crack tip will increase. When it meets the fracture toughness of the specimen, the crack begins to propagate. The process of the stress waves reflects back and forth on the specimen and the repeated superposition increases the duration of the IEAS under low-speed impact.

As the crack expands for the first time and moves over a certain distance, the crack tip energy continuously decreases and suspends the crack growth. It can be seen that the DSIF value of the crack tip decreased rapidly after the crack moved (Figure 9). The DSIF value does not decrease to 0 after the crack growth suspension. Instead, it will increase again until the next fracture toughness is met, and the crack continues to grow. This shows that crack propagation does not occur all at once. After moving a certain distance, the crack tip energy dissipates, and it is necessary to wait for the reflected stress waves to once again generate the crack tip energy to reach the fracture condition.

Figure 10 shows the relationship between the loading rate and the initial fracture toughness of the crack when $a=0 \mathrm{~mm}$. It can be observed that the initial fracture toughness of the specimen increased with the increase in the dynamic loading rate.

To intuitively see the specific condition of the crack while in motion, the image of the motion of the caustic spot is processed. Taking the tip of the precrack as the origin $O$, 


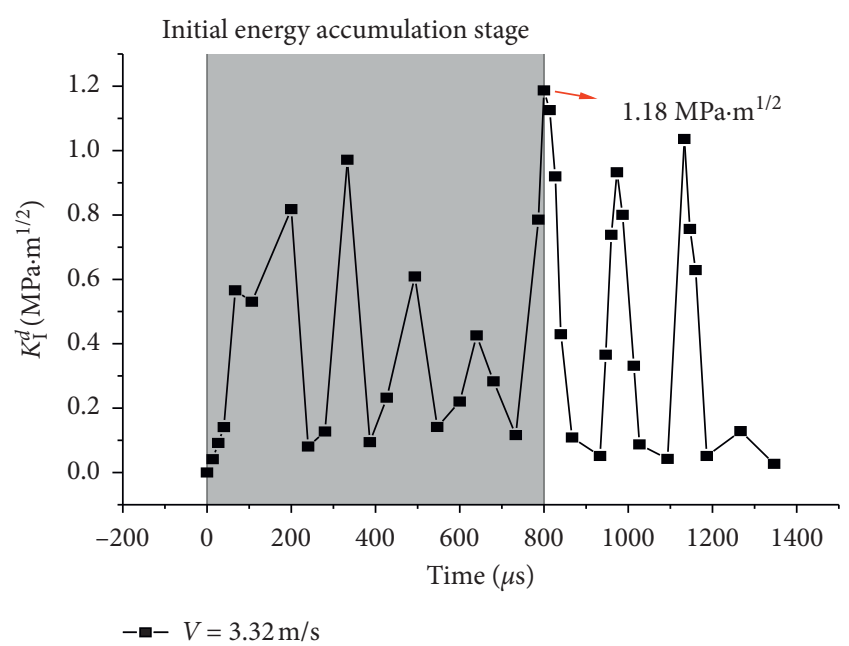

(a)

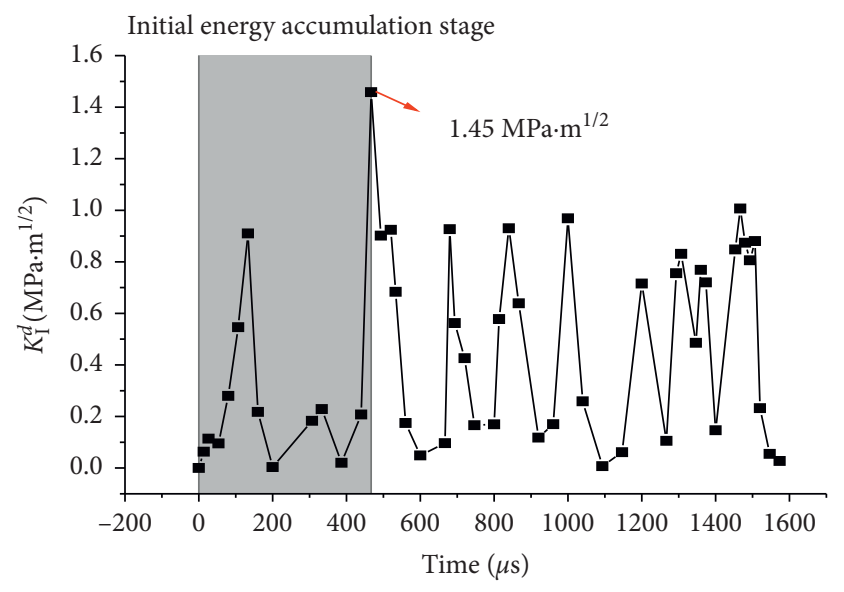

$-\square-V=4.28 \mathrm{~m} / \mathrm{s}$

(c)

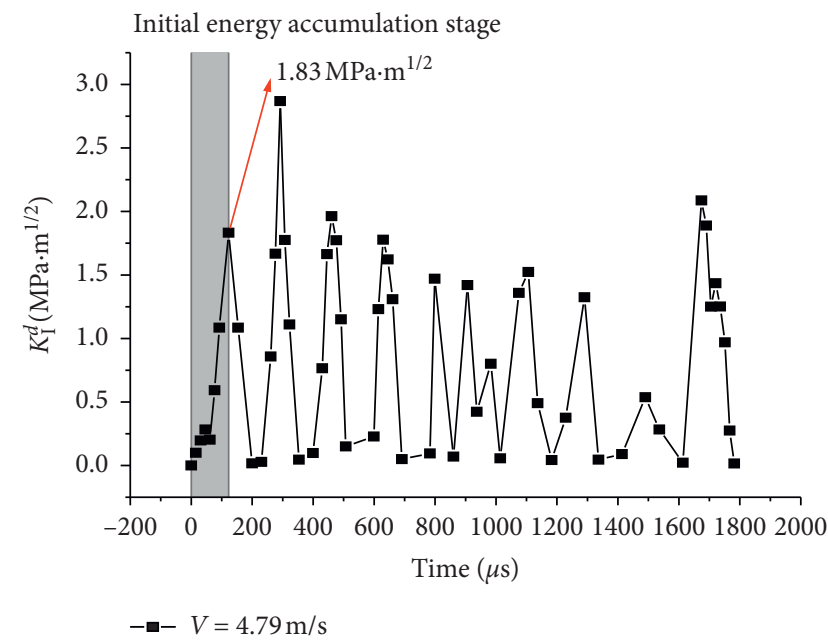

(e)

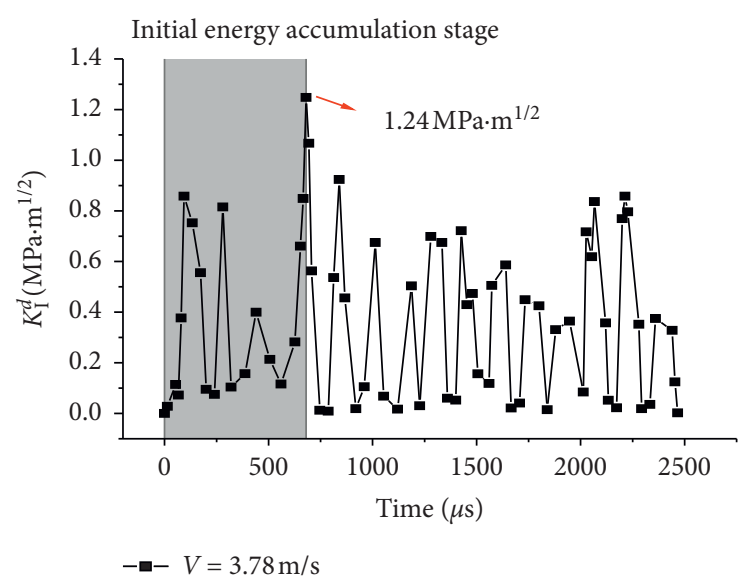

(b)

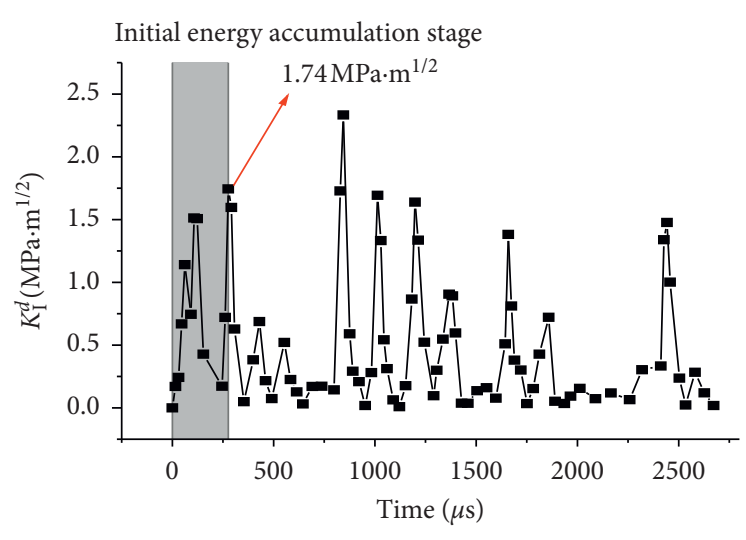

$-V=4.53 \mathrm{~m} / \mathrm{s}$

(d)

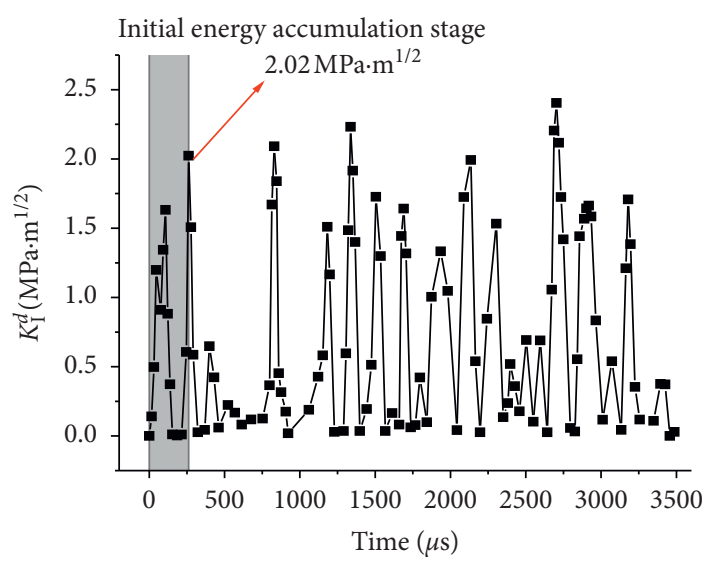

$-\square-V=5.16 \mathrm{~m} / \mathrm{s}$

(f)

FigURE 9: DSIF versus time results for different impact velocities. (a) $V=3.32 \mathrm{~m} / \mathrm{s}$. (b) $V=3.78 \mathrm{~m} / \mathrm{s}$. (c) $V=4.28 \mathrm{~m} / \mathrm{s}$. (d) $V=4.53 \mathrm{~m} / \mathrm{s}$. (e) $V=4.79 \mathrm{~m} / \mathrm{s}$. (f) $V=5.16 \mathrm{~m} / \mathrm{s}$. 


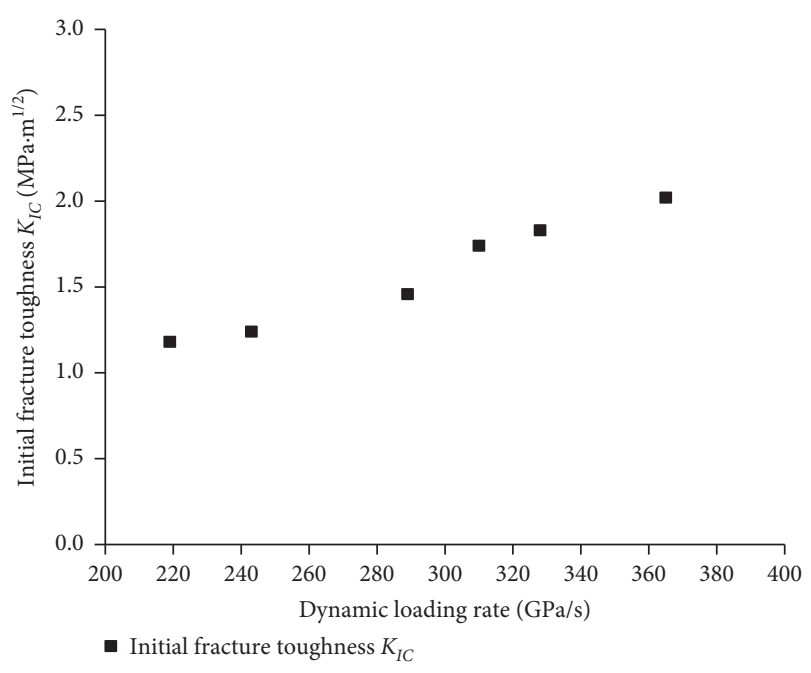

FIGURE 10: Relationship between the initial fracture toughness of the specimen and the dynamic loading rate.

horizontally to the left is the positive direction of $X$, while vertically downward is the positive direction of $Y$. The displacement curves of the crack tip in the $X$ - and $Y$ directions over time were obtained. When $a=0 \mathrm{~mm}$, the crack trajectory is approximately a straight line, and hence the displacement in the $Y$-direction is not considered.

Figure 11 shows the crack tip displacement and velocity versus time. In several sets of tests, the time-history curve of the crack stopped. This means that the crack paused after moving a certain distance and then continued. This corresponds to the change in the DSIF of the crack tip described above. With the increase in the impact speed, the maximum crack displacement also increased. Figure 11(b) shows that the speed of the crack tip constantly changes over time, and the overall trend is rapid increase. As the impact velocity increased, the peak crack-tip velocity also gradually increased. The peak crack-tip velocity of each specimen was not reached at the first displacement, and most were reached in the subsequent displacements.

4.2. Effect of Prefabricated Crack Location. At the impact velocity $V=4.79 \mathrm{~m} / \mathrm{s}$, the dynamic caustic diagram of the fracture process of the tunnel-type specimen, when the precrack is at different positions, is shown in Figure 12. The caustic diagram shows that when the crack position changes, the crack propagation trajectory also changes at the same velocity. When $a=0 \mathrm{~mm}$, the crack propagation trajectory is approximately a straight line that extends along the central axis. The shape of the focal speckle during the entire fracture process is similar to that in Figure 2(a). When $a=5 \mathrm{~mm}$, the crack propagation trajectory is no longer a straight line but curved and downward. When moving toward the vicinity of the central axis of the tunnel, the crack no longer bends down. Comparing the caustic diagrams, we can see that the shape of the caustic spot in this process can be similar to those in Figures 2(a) and 2(b). This shows that the cracks sometimes expand according to the type I fracture law or the mixed type I-II fracture law. When $a=10 \mathrm{~mm}$, the crack propagation trajectory is similar to that when $a=5 \mathrm{~mm}$ and also moves along a curve toward the central axis first. When moving toward the vicinity of the central axis, it does not continue to bend down but moves a distance along the central axis. The difference is that when $a=10 \mathrm{~mm}$, the downward bending of the crack is more obvious, and the first displacement is expanded according to the type I fracture law, and the subsequent expansion process is based on the mixed type I-II fracture law.

Figure 13 shows the DSIF change diagram of the fracture process of the roadway-type specimens when the prefabricated cracks are located at different positions under the impact velocity $V=4.79 \mathrm{~m} / \mathrm{s}$. When the impact speed is constant, the durations of the IEAS of the three sets of test pieces are relatively short, i.e., $122.88 \mu \mathrm{s}, 120 \mu \mathrm{s}$, and $153.6 \mu \mathrm{s}$, respectively. After three groups of test pieces were impacted, their DSIF values constantly changed. When $a=0 \mathrm{~mm}$, because of the type I crack propagation, there is only $K_{I}^{d}$ with the initial fracture toughness of $1.83 \mathrm{MPa} \cdot \mathrm{m}^{1 / 2}$. When $a=5 \mathrm{~mm}$, the crack growth is alternately types I and I-II. The initial fracture toughness is low, with $_{K}^{\mathrm{IC}}=1.28 \mathrm{MPa} \cdot \mathrm{m}^{1 / 2}$ and $K_{\text {IIC }}=0.78 \mathrm{MPa} \cdot \mathrm{m}^{1 / 2}$. When $a=10 \mathrm{~mm}$, the crack expands according to the type I fracture law between $t=0$ and $153.6 \mu \mathrm{s}$, after which the crack expands according to the mixed type I-II fracture law. Thus, when the precrack position is different, it has little effect on the duration of the IEAS, but a greater effect on the initial fracture toughness of the specimen.

When $a=5 \mathrm{~mm}$ and $10 \mathrm{~mm}$, the crack displacement occurs along the $Y$-direction. Hence, the calculation of its speed is based on equation (4). The crack displacement vectors in the $X$ - and $Y$-directions were combined to obtain the actual displacement $Z$. Then, the derivative of the displacement $Z$ over time was obtained, and the change in the crack growth speed $v_{z}$ over time was determined (Figure 14(a)).

The displacement diagram shows that the crack growth versus time curves of the three groups of specimens are also step-shaped (Figure 14(b)). This indicates that even if the prefabricated crack positions are different, the crack growth will still pause and will not be completed at once. At the same impact velocity and $a=0 \mathrm{~mm}$, the crack displacement along the $X$-direction and its peak velocity were the largest. When $a=10 \mathrm{~mm}$, the displacement along the $Y$-direction was the largest. It was also found from Figure $13(\mathrm{c})$ that $K_{\mathrm{II}}^{\mathrm{d}}$ value is larger, indicating that the $K_{\mathrm{II}}^{d}$ value will affect the crack displacement in the $Y$-direction to certain extent.

The reason for the suspension of the crack growth and the drastic change in the DSIF is that when the specimen is subjected to the forces of the incident bar and transmission bar, part of the stress wave either acts on the crack tip or is transmitted to the transmission bar along the specimen. Therefore, the energy cannot be completely applied to the crack tip, and the crack growth stops after a period of propagation. It can be seen from the literature that when the contact surface between the specimen and the transmission bar is small, the specific gravity of the reflected wave is larger, while the specific gravity of the transmitted wave is smaller [33]. Therefore, part of the stress wave transmitted to the 


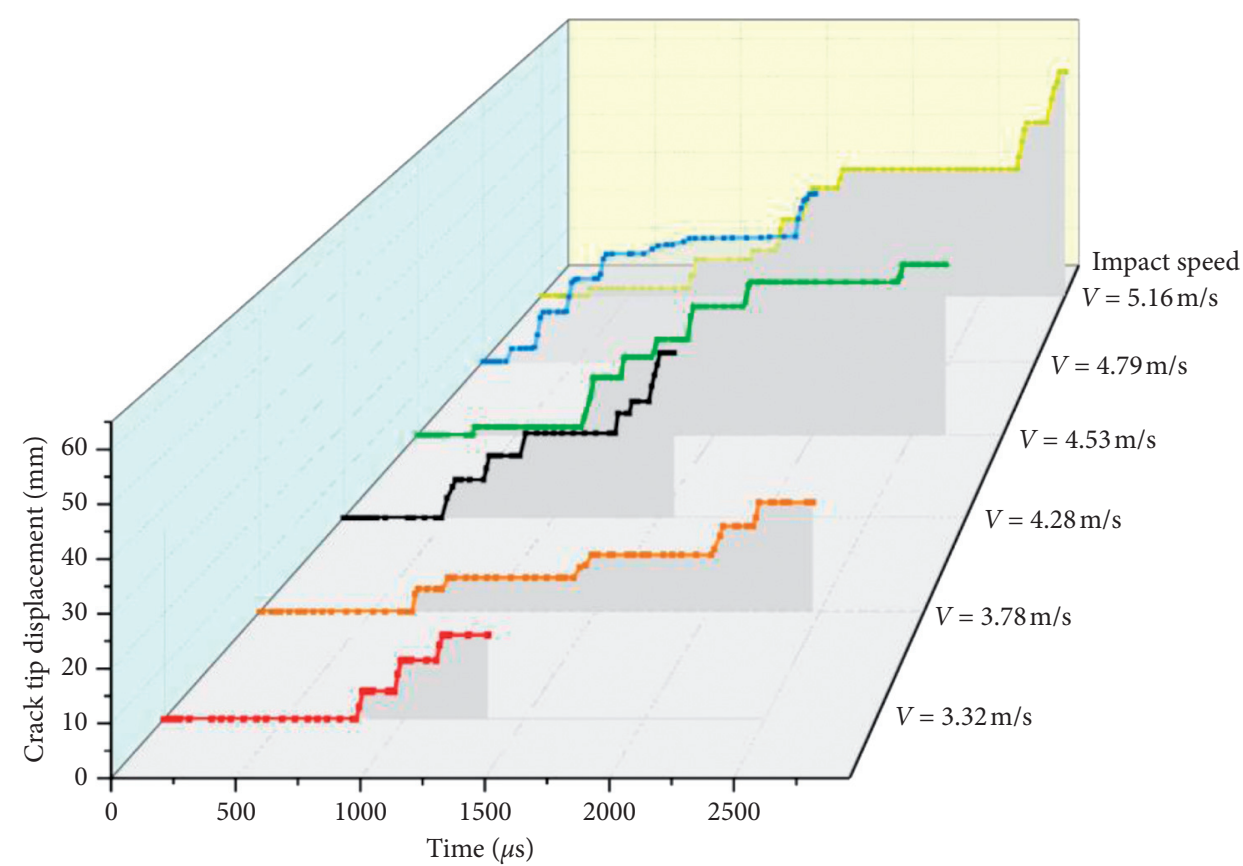

(a)

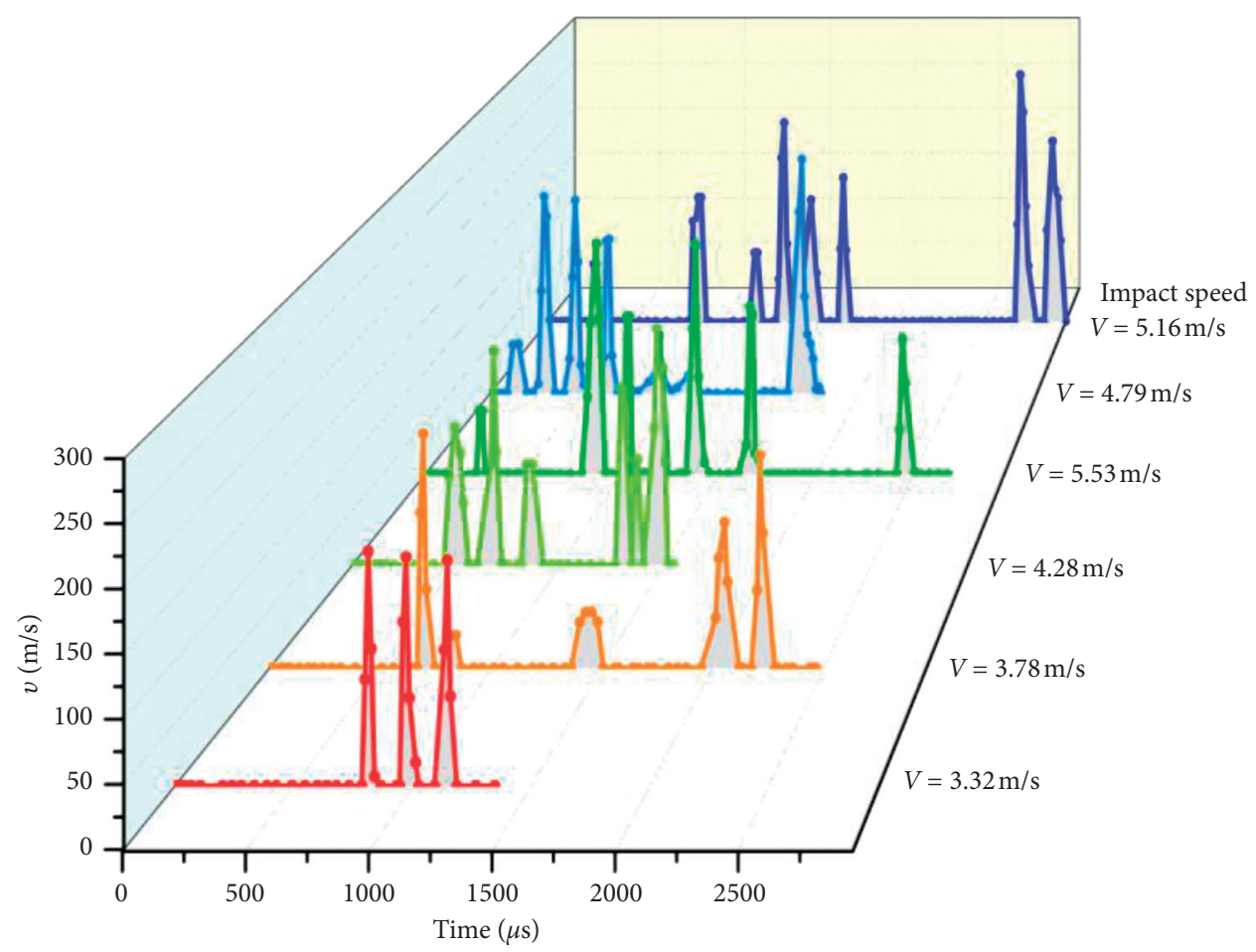

(b)

Figure 11: Crack-tip displacement and velocity versus time under different impact speed conditions. (a) Crack-tip displacement versus time under different impact speed conditions. (b) Crack velocity versus time under different impact speed conditions.

transmission bar was reflected back to the test piece and then transmitted back and forth inside the test piece. This causes the DSIF of the crack tip to keep changing. When the DSIF of the crack tip again exceeds the fracture toughness of the material, the crack growth continues.

Figure 15 is a simplified schematic diagram of the effect of the reflected stress waves on the crack. Owing to the existence of the semicircular arch roadway, when the energy accumulates at the tip of the prefabricated crack for the first time, the stress wave will attenuate to form $P_{d}$ when it is transmitted to a nearby area. The stress wave $P_{i}$ on the upper and lower sides of the semicircular arch roadway does not pass through the roadway. Hence, $P_{i}$ will be greater than $P_{d}$. Therefore, the crack-tip displacement after the energy 


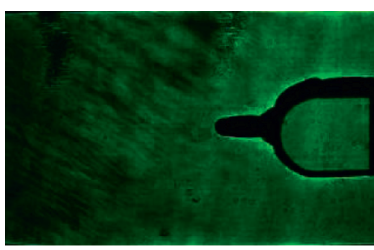

$0 \mu \mathrm{s}$

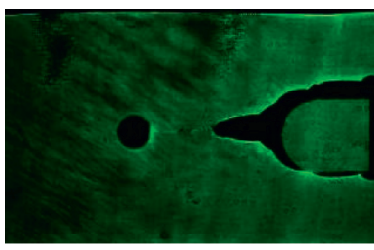

$660.52 \mu \mathrm{s}$

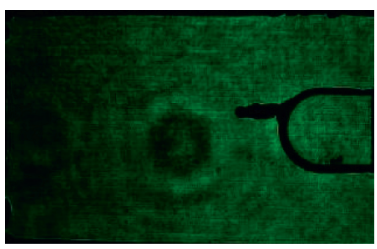

$0 \mu \mathrm{s}$

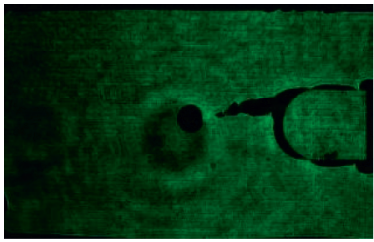

$466.66 \mu \mathrm{s}$

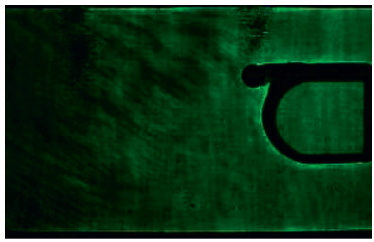

$0 \mu \mathrm{s}$

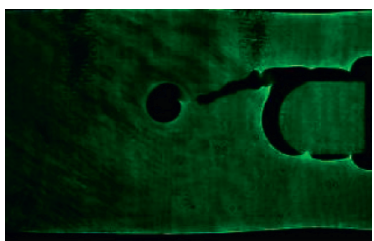

$1213.51 \mu \mathrm{s}$

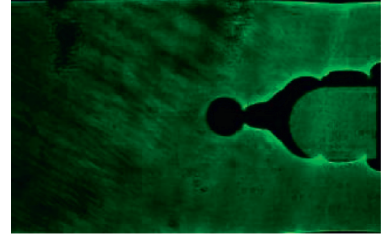

$122.88 \mu \mathrm{s}$

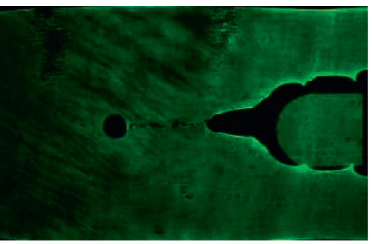

$986.66 \mu \mathrm{s}$

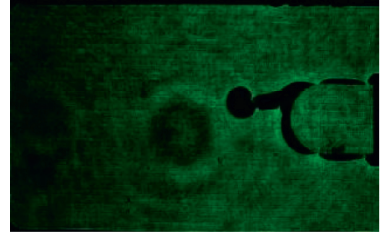

$120 \mu \mathrm{s}$

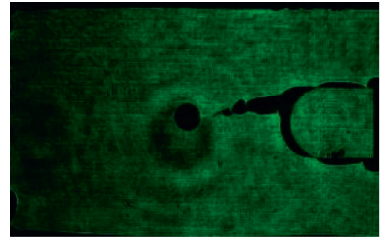

$733.33 \mu \mathrm{s}$

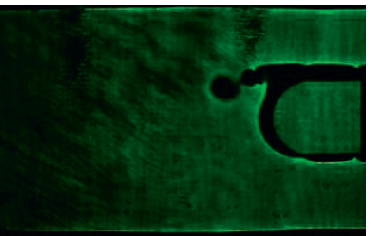

$199.69 \mu \mathrm{s}$

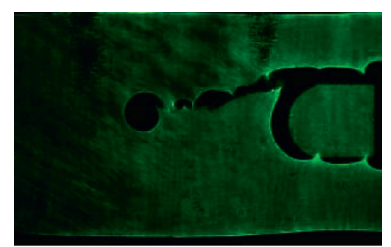

$1582.18 \mu \mathrm{s}$

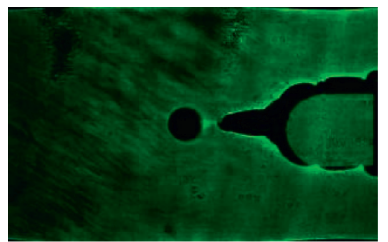

$322.58 \mu \mathrm{s}$

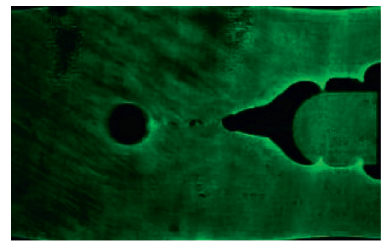

$1453.33 \mu \mathrm{s}$

(a)

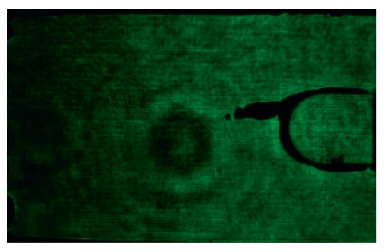

$226.66 \mu \mathrm{s}$

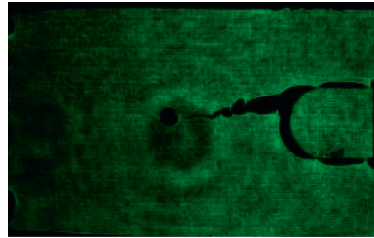

$1213.33 \mu \mathrm{s}$

(b)

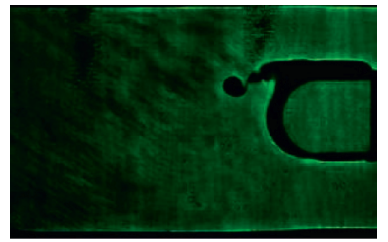

$414.74 \mu \mathrm{s}$

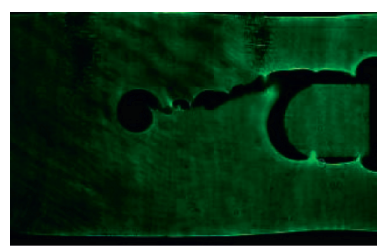

$1674.34 \mu \mathrm{s}$

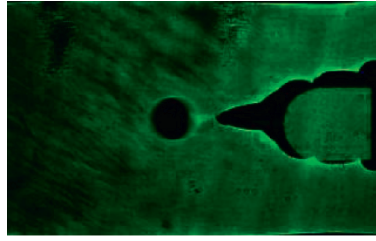

$460.82 \mu \mathrm{s}$

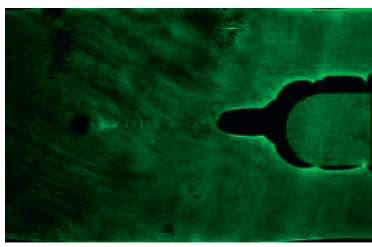

$1766.51 \mu \mathrm{s}$

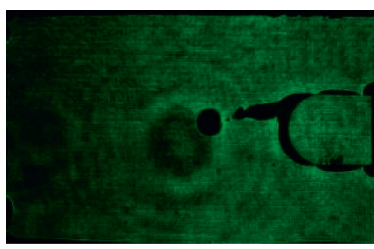

$306.66 \mu \mathrm{s}$

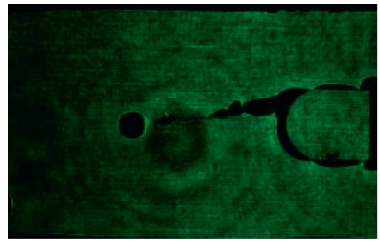

$1906.66 \mu \mathrm{s}$

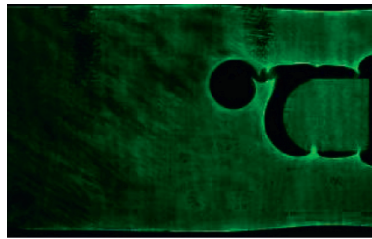

$860.21 \mu \mathrm{s}$

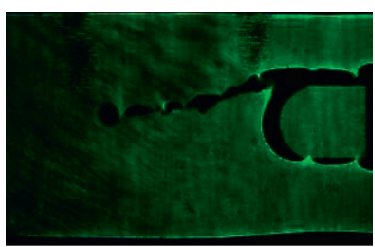

$1950.84 \mu \mathrm{s}$

(c)

Figure 12: Dynamic caustic image patterns at the crack tip in specimens with different locations of prefabricated cracks. (a) $a=0 \mathrm{~mm}$. (b) $a=5 \mathrm{~mm}$. (c) $a=10 \mathrm{~mm}$.

accumulation is completed will be deflected downward instead of upward. As the crack moves, it remains affected by the stress wave. Because the crack trajectory is an arc, the stress wave is decomposed along the normal and tangential directions of the arc to obtain $P_{r}$ and $P_{t}$, which can be expressed as 

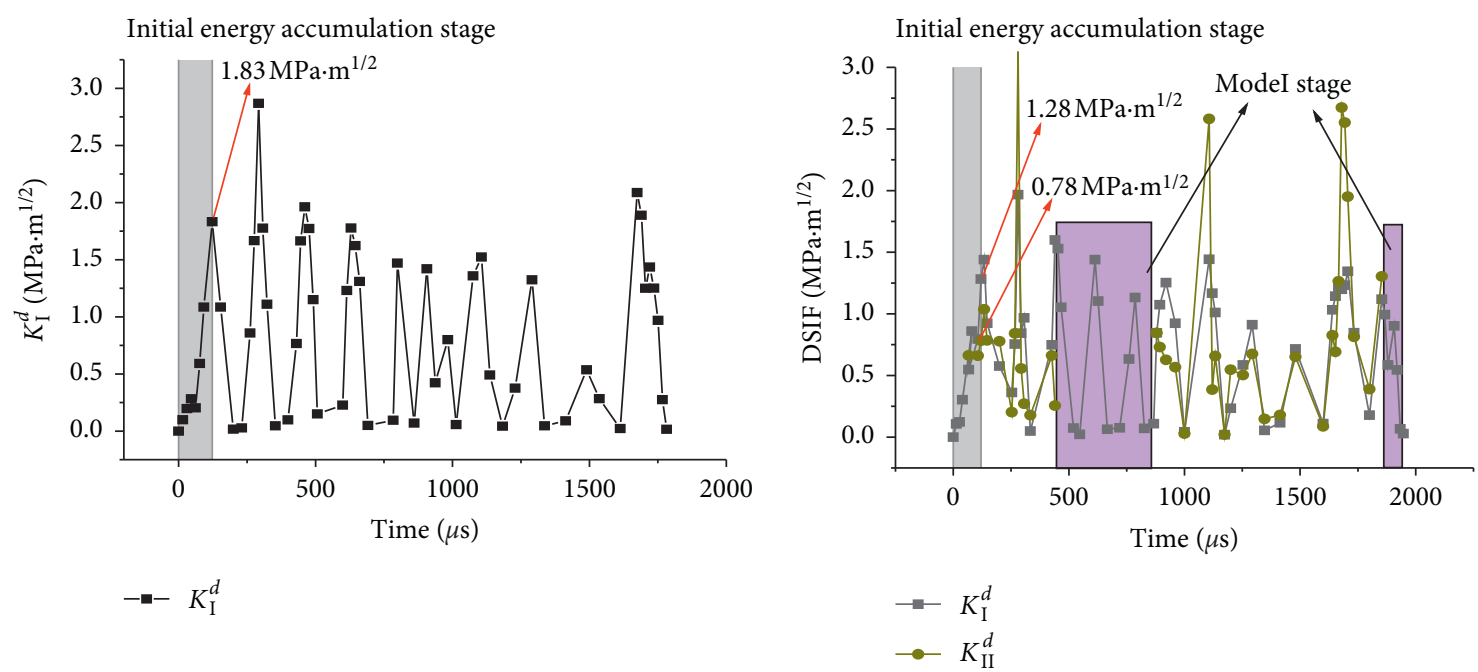

(a)

(b)

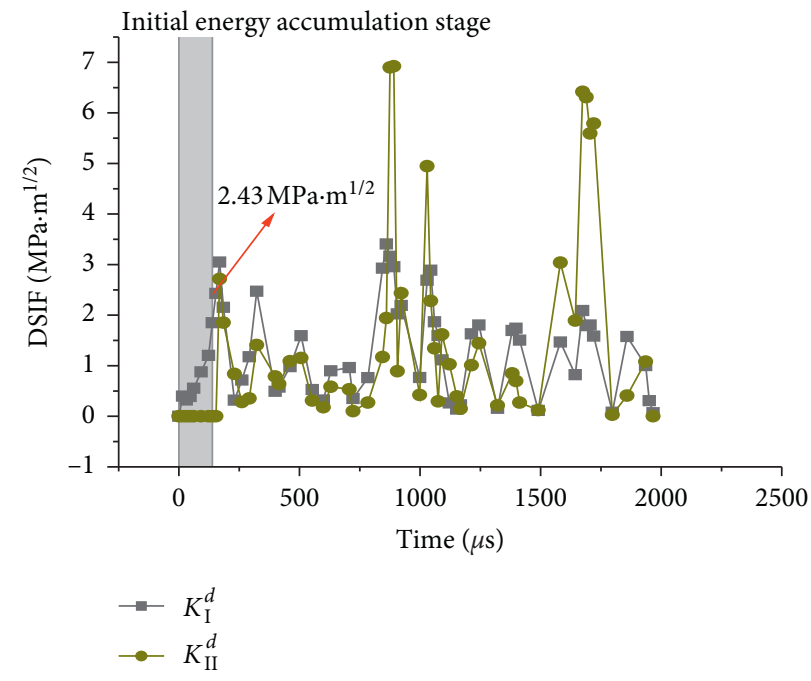

(c)

FIGURE 13: DSIF versus time results for different precrack locations. (a) $a=0 \mathrm{~mm}$. (b) $a=5 \mathrm{~mm}$. (c) $a=10 \mathrm{~mm}$.

$$
\left\{\begin{array}{l}
P_{1 r}=P_{1} \cdot \cos \alpha, P_{1 t}=P_{1} \cdot \sin \alpha \\
P_{2 r}=P_{2} \cdot \cos \alpha, P_{2 t}=P_{2} \cdot \sin \alpha \\
\cdots \\
\cdots \\
P_{m r}=P_{m} \cdot \cos \alpha, P_{m t}=P_{m} \cdot \sin \alpha
\end{array} .\right.
$$

As the angle $\alpha$ increased, the normal component of the stress wave gradually decreased, while the tangential component gradually increased. When $\alpha=90^{\circ}$, the normal component of the stress wave is 0 , the crack no longer moves in a curve, and the tangential component reaches its maximum, which is equal to the magnitude of the stress wave at this time.

\section{Numerical Modelling}

To verify the crack propagation law of the roadway under impact, the commercial finite element software ABAQUS was used to simulate the fracture process. The XFEM of ABAQUS is widely used to study the deformation and fracture of solid materials under stress.

5.1. Meshing of the Specimen. In the numerical simulations, it was assumed that the material changes were caused by crack growth. To ensure that both the experimental and simulated impact loads are subjected to uniform one-dimensional loads, the output terminal consisting of the bullet and incident rod was used for modelling (the output terminal load is the same as the test). The shear modulus of the bullet and incident bar is $81 \mathrm{GPa}$, Poisson's ratio is $V_{d 2}=0.26$, and the material density is $7900 \mathrm{~kg} / \mathrm{m}^{3}$. The bullet and incident bar models consist of 412 and 1326 elements, respectively, and the size is $10 \mathrm{~mm}$ (Figure 16). The shear modulus of the PMMA is $1.28 \mathrm{GPa}$, Poisson's ratio $V_{d 1}=0.31$, and the material density is $1180 \mathrm{~kg} / \mathrm{m}^{3}$. The triangular CPS3 elements were adopted to simulate the region near the crack tip, 


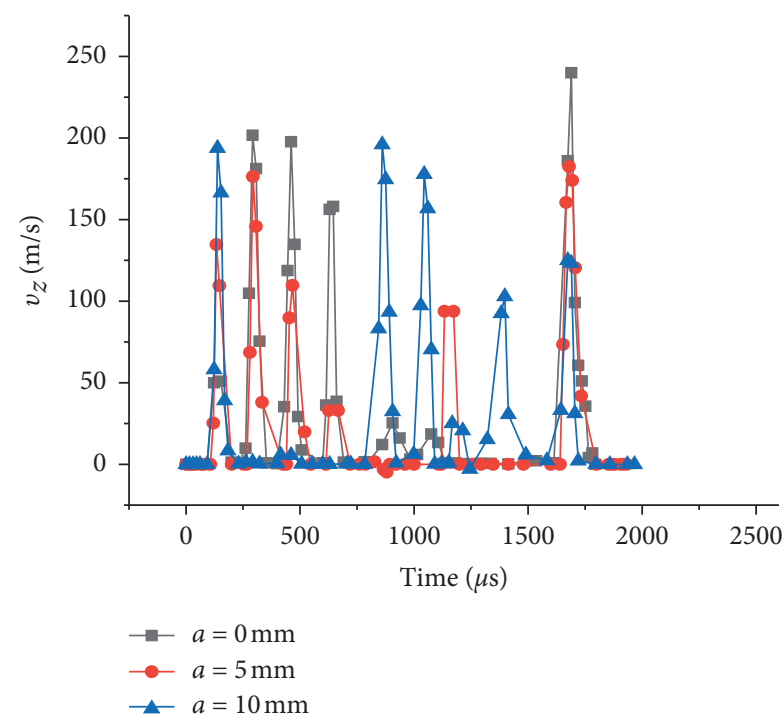

(a)

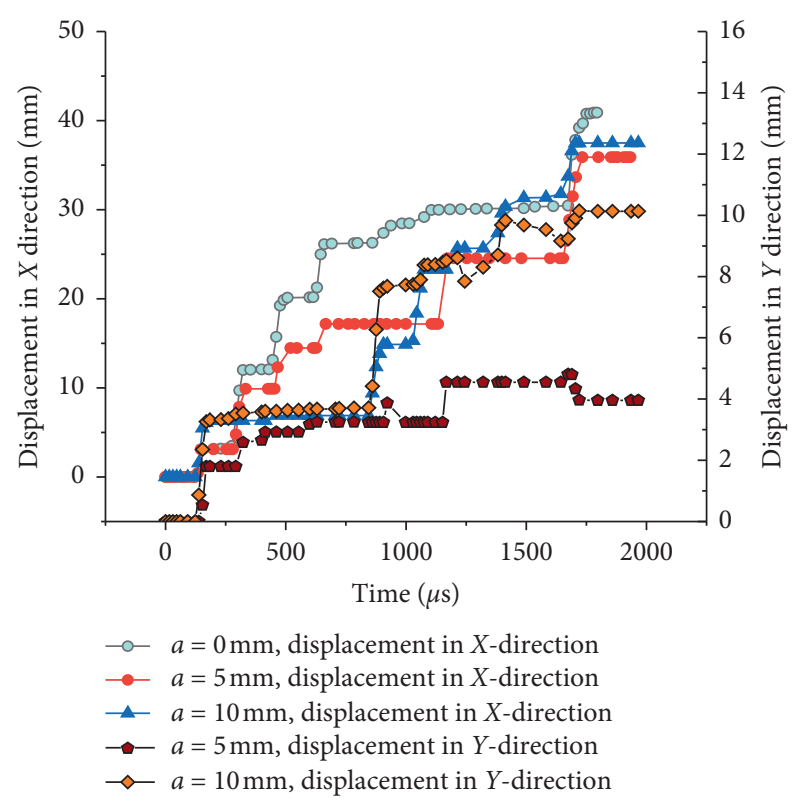

(b)

Figure 14: Crack-tip displacement and velocity versus time under different locations of prefabricated cracks. (a) Crack velocity versus time under different locations of prefabricated cracks. (b) Crack-tip displacement versus time under different locations of prefabricated cracks.

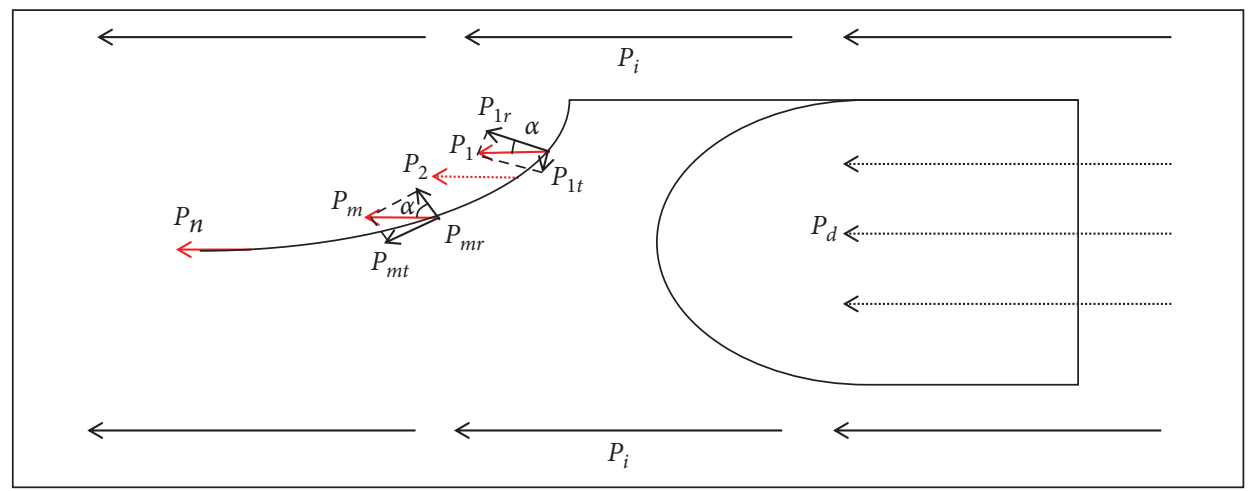

FiguRE 15: Effect of stress wave on the crack.

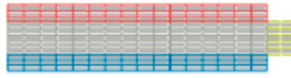

Figure 16: Case of a meshed output bar.

while the quadrilateral CPS4R solid elements were used for other regions (Figure 17). It consists of 11982 elements with a mesh size of $0.05 \mathrm{~mm}$.

5.2. Numerical Simulation Results. Figure 18 shows the stress contours of the crack tip at different times when the specimen is in the IEAS after impact, when $a=0 \mathrm{~mm}$. At $t=326.45 \mu \mathrm{s}$, the crack started to propagate.

According to the linear elastic fracture theory, the stress intensity factor at the tip of a mode I crack can be expressed as

$$
K_{I}^{d}=\lim _{r \longrightarrow 0} \sqrt{2 \pi r} \sigma
$$

where $r$ is the distance from the measuring point to the crack tip and $\sigma$ is the principal stress at the crack tip. The crack tip does not move during the energy accumulation stage. To ensure convergence, a point within $0.05 \mathrm{~mm}$ of the crack tip was taken for measurement.

The crack fracture test process at different impact velocities was simulated for $a=0 \mathrm{~mm}$. The stress value at the crack tip when the crack moves for the first time was selected, combined with equation (13), and the corresponding stress intensity factor at the crack tip was calculated. The initial fracture toughness of the crack was obtained and compared with the experimental value (Figure 19). The initial fracture toughness obtained by the numerical calculation increased with the increase in the impact velocity, 


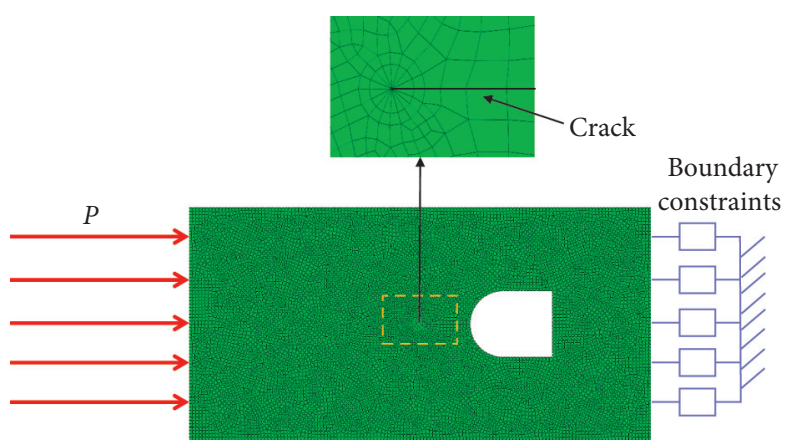

FIgURE 17: Typical mesh of specimen in ABAQUS.

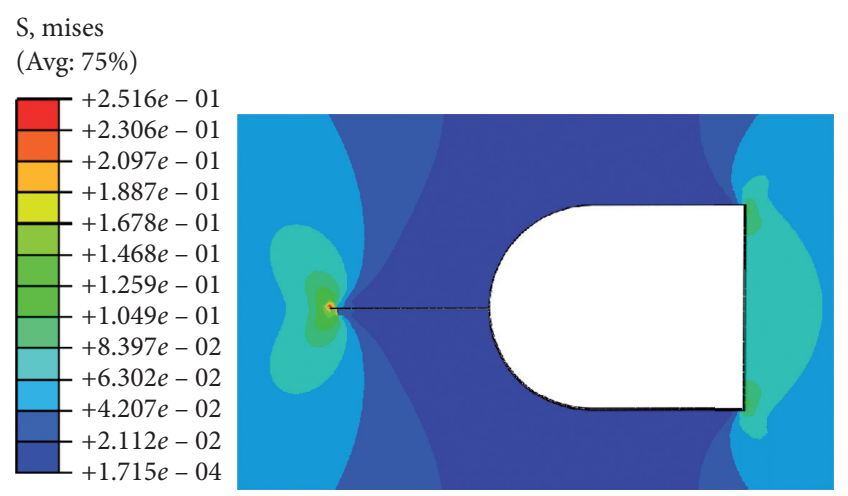

(Avg: 75\%)

(a)
S, mises
(Avg: $75 \%)$

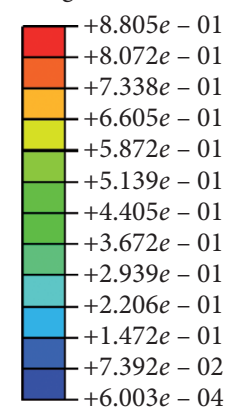

$+6.003 e-04$

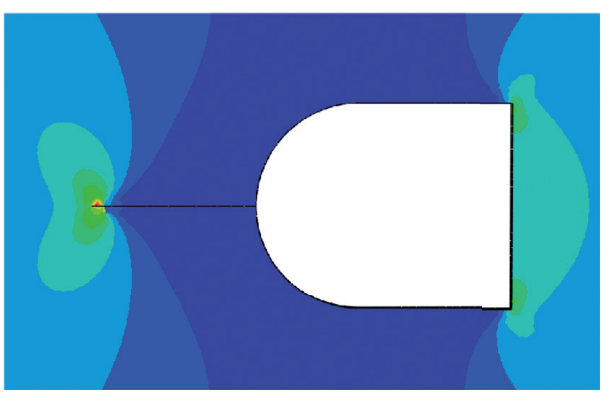

(b)

S, mises (Avg: 75\%)
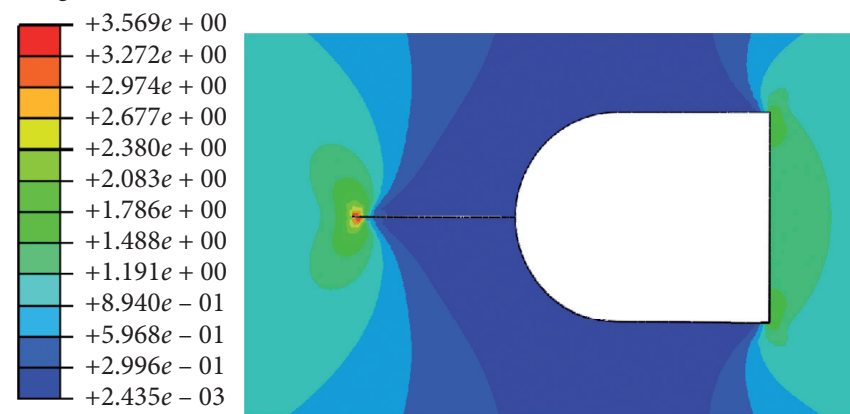

(c)

FiguRE 18: Stress contours of the crack tip at different times in the energy accumulation stage. (a) $50.53 \mu \mathrm{s}$. (b) $175.69 \mu \mathrm{s}$. (c) $326.46 \mu \mathrm{s}$.

which agrees with the experimental results. At the same speed, the fracture toughness obtained by the numerical simulations is slightly larger than the experimental value, which may be attributed to the additional energy acting on the crack tip in the numerical calculations. In the actual test, after the stress wave was transmitted to the crack tip, part of the stress wave continued to transmit to the transmission bar. As a result, the energy acting on the crack tip was less than that in the numerical simulations.
The fracture process of the specimen with the preset crack at different positions was simulated at the same impact velocity. The crack propagation trajectory was obtained as shown in Figure 20. The comparison of the crack paths obtained from the tests and numerical simulations (Figure 21) showed good agreement. However, the numerical simulation results showed a smoother crack trajectory compared with the test results because the friction force and material uniformity of the specimen cannot be completely 


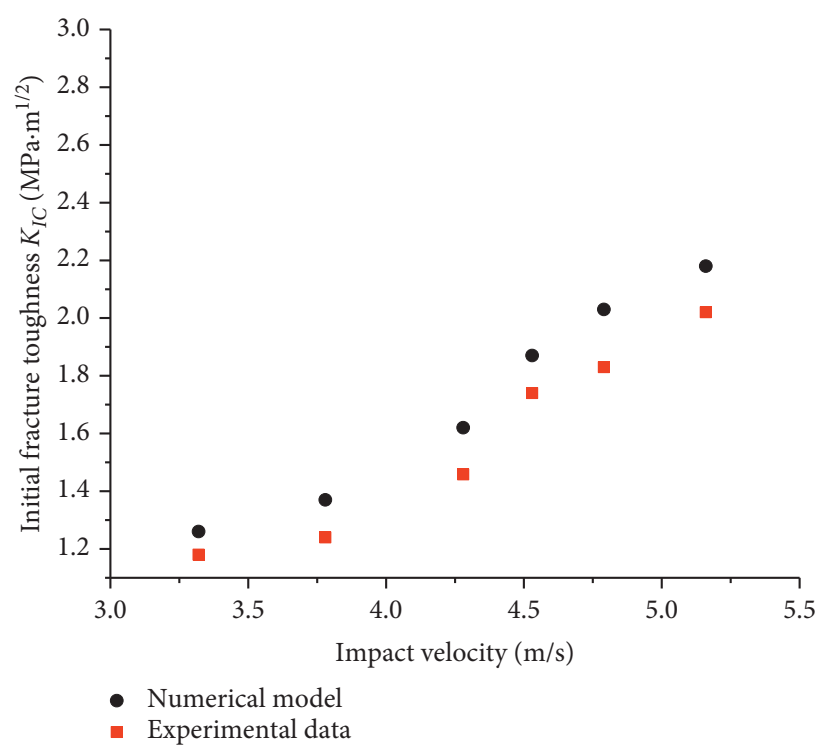

FIGURE 19: Numerical simulation and experimental results for the initial fracture toughness versus impact velocity.

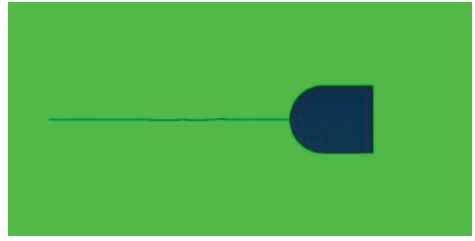

(a)

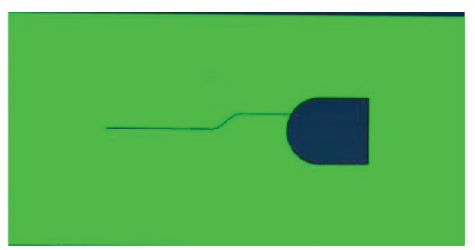

(b)

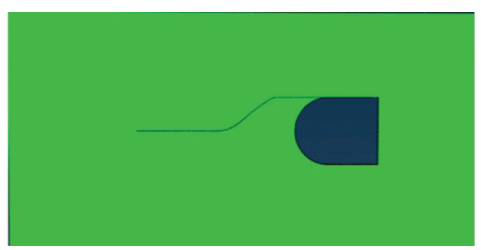

(c)

Figure 20: Crack growth trajectories under different locations of prefabricated cracks. (a) $a=0 \mathrm{~mm}$. (b) $a=5 \mathrm{~mm}$. (c) $a=10 \mathrm{~mm}$.

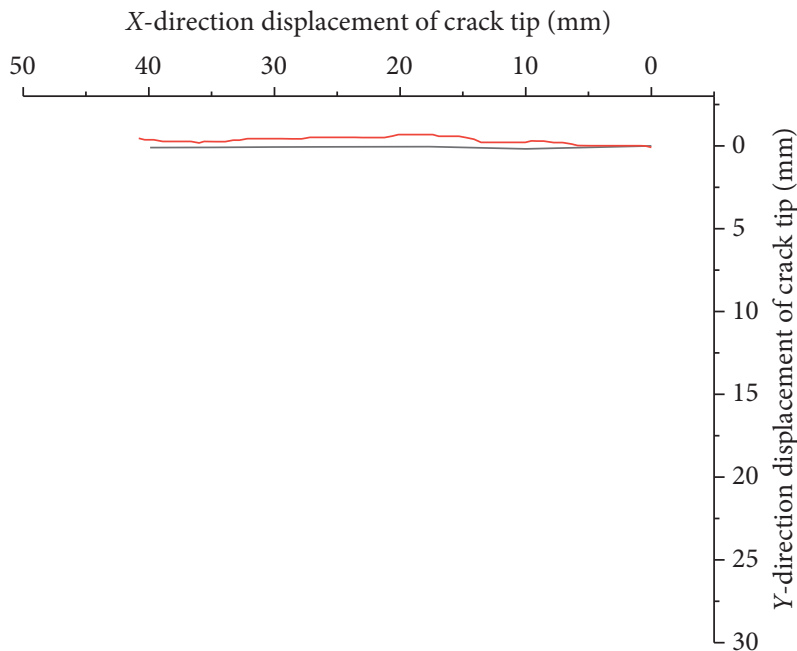
$X$-direction displacement of crack tip $(\mathrm{mm})$

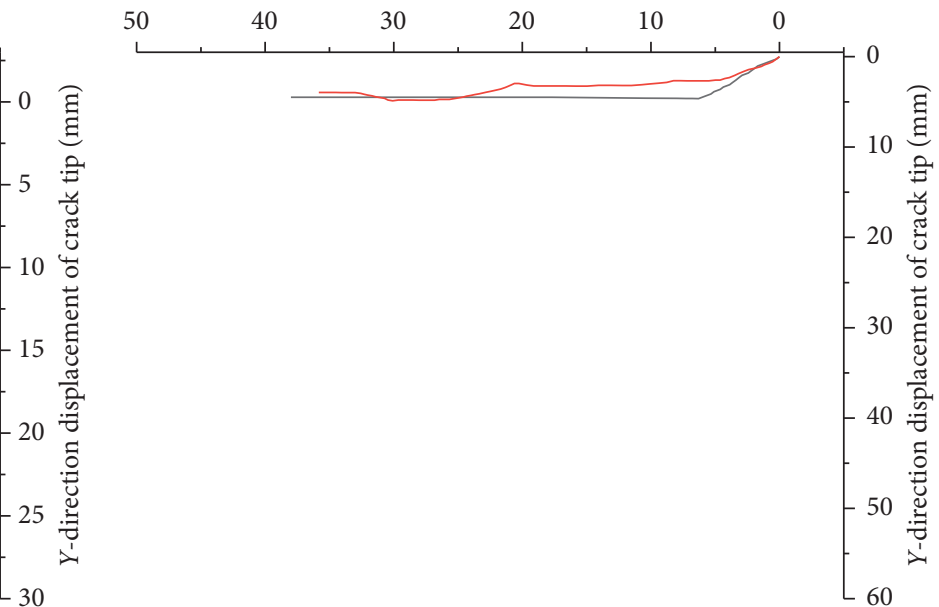

$a=0 \mathrm{~mm}$, numerical model $a=0 \mathrm{~mm}$, experimental data
_ $a=5 \mathrm{~mm}$, numerical model $a=5 \mathrm{~mm}$, experimental data

FIgure 21: Continued. 


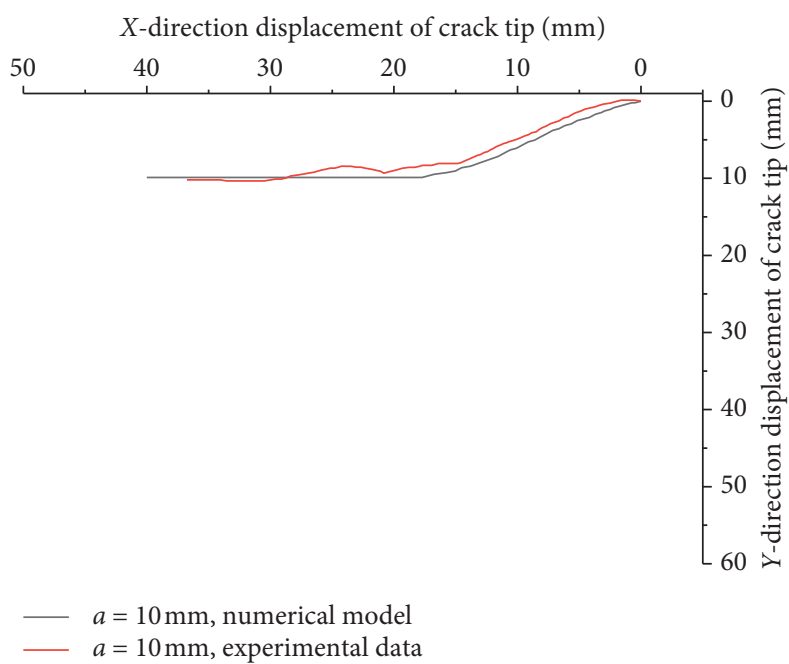

(c)

Figure 21: Comparison of the crack paths for different precrack locations. (a) $a=0 \mathrm{~mm}$. (b) $a=5 \mathrm{~mm}$. (c) $a=10 \mathrm{~mm}$.

excluded from the test. Therefore, the crack trajectory obtained from the tests fluctuated within a small range.

\section{Conclusions}

In this study, the dynamic fracture processes of tunnel specimens under impact loading were investigated using the DLDC and SHPB methods. The effects of the impact velocity and location of the prefabricated crack on the crack propagation were studied. The conclusions are summarized as follows:

(1) The SHPB system was used as the loading method to accurately control the dynamic load. The DLDC system was used to observe the crack growth process and can be used to record and analyze the entire process from impact to stress wave disappearance. It is useful to study the crack growth process under one-dimensional stress.

(2) When the impact velocity changes, the initial fracture toughness increased with the increase in the impact velocity. The duration of the crack IEAS tended to decrease, the crack displacement increased, and the peak crack growth velocity increased.

(3) At different precrack positions, the same impact velocity will result in different crack propagation trajectories. When $a=0 \mathrm{~mm}$, the crack grows according to the type I fracture law, and the displacement was largest in the $X$-direction. When $a=5 \mathrm{~mm}$, the crack propagation process alternated between type I and mixed type I-II. When $a=10 \mathrm{~mm}$, the crack displacement in the $Y$-direction and the initial fracture toughness were the largest.

(4) The experiment was simulated by a numerical method, which showed that the initial fracture toughness of the specimen changed with the impact velocity, the same as in the experiment. The crack trajectory is similar to the test trajectory when the precrack position is different. The numerical simulations accurately predicted and verified the test results.

\section{Data Availability}

Data are not made available as the NSF supporting the project is confidential.

\section{Conflicts of Interest}

The authors declare that they have no conflicts of interest regarding the publication of this paper.

\section{Acknowledgments}

The authors thank Dr. Cheng Chen and Dr. Liyun Yang for their help to perform the experiments and acknowledge the support from the State Key Development Program for Basic Research of China under Grant no. 2016YFC0600903, the Fundamental Research Funds for the Central Universities (No. FRF-TP-20-072A1), and the National Natural Science Foundation of China under Grant no. 51774287, as the independent selection key research project of State Key Laboratory for Geo-Mechanics and Deep Underground Engineering in the School of Mechanics and Civil Engineering at China University of Mining and Technology, Beijing, China.

\section{References}

[1] J. Zhao, Y. X. Zhou, A. M. Hefny et al., "Rock dynamics research related to cavern development for ammunition storage," Tunnelling and Underground Space Technology, vol. 14, no. 4, pp. 513-526, 1999.

[2] S. Mishra, T. Chakraborty, D. Basu, and N. Lam, "Characterization of sandstone for application in blast analysis of 
tunnel," Geotechnical Testing Journal, vol. 43, pp. 351-382, 2020.

[3] J. T. Chen, Y. Yuan, and H. T. Yu, "Dynamic response of segmental lining tunnel," Geotechnical Testing Journal, vol. 43, pp. 660-682, 2020.

[4] L. Tian and Z.-X. Li, "Dynamic response analysis of a building structure subjected to ground shock from a tunnel explosion," International Journal of Impact Engineering, vol. 35, no. 10, pp. 1164-1178, 2008.

[5] W. D. Ortlepp, T. R. Stacey, and T. R. Stacey, "Performance of tunnel support under large deformation static and dynamic loading," Tunnelling and Underground Space Technology, vol. 13, no. 1, pp. 15-21, 1998.

[6] D. M. Guo, K. Liu, R. S. Yang, and Y. Li, "Simulation experiments on the mechanism of adjacent tunnel crack extension induce-d by explosion load," Journal of Vibration and Shock, vol. 2, pp. 178-183, 2016.

[7] D. M. Guo, K. Liu, R. S. Yang et al., "Experimental research on the influence of blasting on the inclined crack in the backblasting side of nearby roadway," Journal of Mining and Safety Engineering, vol. 32, pp. 99-104, 2015.

[8] L. Zhou, Z. Zhu, Y. Dong, Y. Fan, Q. Zhou, and S. Deng, "The influence of impacting orientations on the failure modes of cracked tunnel," International Journal of Impact Engineering, vol. 125, pp. 134-142, 2019.

[9] L. Zhou, Z. Zhu, R. Liu, Y. Fan, Y. Dong, and P. Ying, "Investigation on fracture properties of single-flawed tunnel model under medium-to-low-speed impacts," Acta Mechanica Solida Sinica, vol. 33, no. 2, pp. 205-225, 2020.

[10] L. Zhou, Z. Zhu, M. Wang, P. Ying, and Y. Dong, "Dynamic propagation behavior of cracks emanating from tunnel edges under impact loads," Soil Dynamics and Earthquake Engineering, vol. 105, pp. 119-126, 2018.

[11] L. Zhou, Z. Zhu, H. Qiu, X. Zhang, and L. Lang, "Study of the effect of loading rates on crack propagation velocity and rock fracture toughness using cracked tunnel specimens," International Journal of Rock Mechanics and Mining Sciences, vol. 112, pp. 25-34, 2018.

[12] L. Zhou, Z. Zhu, Y. Dong, P. Ying, and M. Wang, "Study of the fracture behavior of mode I and mixed mode I/II cracks in tunnel under impact loads," Tunnelling and Underground Space Technology, vol. 84, pp. 11-21, 2019.

[13] Y. Fan, Y. L. Zhao, Z. M. Zhu et al., "Stress intensity factors for a tunnel containing a radial crack under compression," Advances in Mechanical Engineering, vol. 12, pp. 1-10, 2017.

[14] F. Huang, H. Zhu, Q. Xu, Y. Cai, and X. Zhuang, "The effect of weak interlayer on the failure pattern of rock mass around tunnel - scaled model tests and numerical analysis," Tunnelling and Underground Space Technology, vol. 35, pp. 207-218, 2013.

[15] H. Feng, X. Zhang, D. Gou, J. Chun, X. Ou, and X. Zhou, "Cause investigation of side-wall cracking in an operational tunnel," Engineering Failure Analysis, vol. 101, pp. 157-171, 2019.

[16] D. Grégoire, H. Maigre, J. Réthoré, and A. Combescure, "Dynamic crack propagation under mixed-mode loading comparison between experiments and X-FEM simulations," International Journal of Solids and Structures, vol. 44, no. 20, pp. 6517-6534, 2007.

[17] Z. H. Teng, F. Sun, S. C. Wu et al., "An adaptively refined XFEM for the dynamic fracture problems with micro-defects," Theoretical and Applied Fracture Mechanics, vol. 103, pp. 1087-1106, 2019.

[18] C. X. Li, Y. T. Zhang, and C. An, "Study on the dynamic propagation and numerical simulation of mode I and mixed mode I - II cracks in PMMA specimens with unilateral semicircular holes," Journal of Mining Science and Technology, vol. 5, pp. 490-501, 2020.

[19] S. Kumar, I. V. Singh, B. K. Mishra, and A. Singh, "New enrichments in XFEM to model dynamic crack response of 2D elastic solids," International Journal of Impact Engineering, vol. 87, pp. 198-211, 2016.

[20] P. Manogg, Anwendung der Schattenoptik zur Untersuchung des Zerreissvorganges von Platten, University of Freiburg, Breisgau, Germany, 1964.

[21] P. S. Theocaris, "Reflected shadow method for the study of constrained zones in cracked plates," Applied Optics, vol. 10, pp. 2240-2247, 1972.

[22] P. S. Theocaris, E. E. Gdoutos, and E. Gdoutos, "The modified Dugdale-Barenblatt model adapted to various fracture configurations in metals," International Journal of Fracture, vol. 10, no. 4, pp. 549-564, 1974.

[23] L. Y. Yang, R. S. Yang, and P. Xu, "Caustics method combines with laser \& digital high-speed camera and its applications," Journal of China University of Mining \& Technology, vol. 2, pp. 31-37, 2013.

[24] P. Xu, R. Yang, Y. Guo, and Z. Guo, "Investigation of the blast-induced crack propagation behavior in a material containing an unfilled joint," Applied Sciences, vol. 10, no. 13, p. 4419, 2020.

[25] P. Xu, R. S. Yang, Y. Guo et al., "Experimental and numerical investigation of the interaction between blast wave and precrack in a defected material," Applied Optics, vol. 35, pp. 9718-9727, 2019.

[26] R. Yang, C. Ding, Y. Li, L. Yang, and Y. Zhao, "Crack propagation behavior in slit charge blasting under high static stress conditions," International Journal of Rock Mechanics and Mining Sciences, vol. 119, pp. 117-123, 2019.

[27] J. F. Kalthoff, "The shadow optical method of caustics," Photoelasticity, vol. 9, pp. 109-120, 1986.

[28] W. Yao, H.-W. Liu, Y. Xu, K. Xia, and J. Zhu, “Thermal degradation of dynamic compressive strength for two mortars," Construction and Building Materials, vol. 136, pp. 139-152, 2017.

[29] Y. X. Zhou, K. W. Xia, X. B. Li et al., "Suggested methods for determining the dynamic strength parameters and model fracture toughness of rock materials," International Journal of Rock Mechanics and Mining Sciences, vol. 49, pp. 105-112, 2011.

[30] P. Xu, R. S. Yang, Y. Guo et al., "Experimental investigation of the stress field around the crack tip in a polymer material under dynamic loading," Optical Engineering, vol. 59, Article ID 044105, 2020.

[31] M. R. Ayatollahi, A. R. Torabi, and M. Firoozabadi, "Theoretical and experimental investigation of brittle fracture in V-notched PMMA specimens under compressive loading," Engineering Fracture Mechanics, vol. 135, pp. 187-205, 2015.

[32] T. Karimzada and H. Maigre, "Modelisation of dynamic crack propagation criteria," Journal De Physique IV, vol. 2, pp. 13-18, 2000.

[33] N. N. Li and H. B. Li, "An SHPB test study on wave propagation across rock masses with different contact area ratios of joint," International Journal of Impact Engineering, vol. 105, pp. 109-116, 2017. 